University of Tennessee Health Science Center

UTHSC Digital Commons

\title{
$5-2011$
}

\section{Analysis of Out-of-Pocket Expenditures of Oral Oncologics for Tennessee Recipients of Medicare Part D}

\author{
Eve Carolyn Elias \\ University of Tennessee Health Science Center
}

Follow this and additional works at: https://dc.uthsc.edu/dissertations

Part of the Health and Medical Administration Commons, Health Services Research Commons, and the Pharmacoeconomics and Pharmaceutical Economics Commons

\section{Recommended Citation}

Elias, Eve Carolyn , "Analysis of Out-of-Pocket Expenditures of Oral Oncologics for Tennessee Recipients of Medicare Part D" (2011). Theses and Dissertations (ETD). Paper 67. http://dx.doi.org/10.21007/ etd.cghs.2011.0081.

This Thesis is brought to you for free and open access by the College of Graduate Health Sciences at UTHSC Digital Commons. It has been accepted for inclusion in Theses and Dissertations (ETD) by an authorized administrator of UTHSC Digital Commons. For more information, please contact jwelch30@uthsc.edu. 


\title{
Analysis of Out-of-Pocket Expenditures of Oral Oncologics for Tennessee Recipients of Medicare Part D
}

\begin{abstract}
Background: There are few studies that examine patients' costs of oral oncology drugs from Medicare Part D plan providers. These drugs can impose a financial burden to beneficiaries, and, due to their cost, place beneficiaries in the coverage gap in a short period of time. In addition to examining costs, there is little published concerning the potential impact of drug utilization management techniques on access to these drugs in Medicare Part D plans. This study examined the roles of prior authorization, step-therapy, and placement of drugs in higher formulary tiers on patients' out-of-pocket costs, and access to therapy.

Methods: A cost analysis of pricing structure data for nine oral oncology drugs from the 48 Medicare Part D stand-alone plans in Tennessee in 2009. Out-of-pocket costs per drug on an annual basis, copayments per claim, monthly premiums, and deductibles as well as an analysis of the time to the coverage gap, and patient expenses beyond the catastrophic limit are examined. This analysis includes a summary of the changes to drug utilization management techniques to these drugs on the plans from 2008 to 2009 and examines their impact on members' out-of-pocket expenses.
\end{abstract}

Results: Of the one million eligible seniors in Tennessee, only about $43 \%$ were enrolled in a Medicare Part D plan in 2009. There were 48 plans offered in 2009 with a variety of deductibles, premiums, and costsharing strategies. For the drugs in the study, imatinib, lenalidomide, sorafenib, erlotinib, dasatinib, sunitinib, vorinostat, nilotinib, and lapatinib, the annual out-of-pocket costs for each drug varied from $\$ 0$ to a maximum of $\$ 1,133$, based on plan design. Bivariate regression analysis showed that monthly premiums, deductibles, and cost-sharing are all precise predictors of out-of-pocket expenses $(p<.001)$ and demonstrated to what extent each of these parameters are important to out-of-pocket expenses. For every $\$ 1$ increase in monthly premiums, out-of-pocket costs increased by $\$ 14.27$ for imatinib and $\$ 14.29$ for the remainder of the study drugs. A cost sharing increase of $1 \%$ is associated with a $\$ 41.45$ increase in out-of-pocket expenses for imatinib. That same $1 \%$ increase in cost sharing resulted in a $\$ 41.16$ increase in out-of-pocket expenses for the remainder of the study drugs. Annual deductibles provide cost savings to beneficiaries; for every dollar increase there is a significant reduction in annual out-of-pocket expenses of $\$ 1.45$. Drug utilization management tools such as prior authorization resulted in cost savings to members for all study drugs except for vorinostat and lapatinib; however, the results were not statistically significant.

Conclusions: There is little doubt that for seniors lacking prescription drug benefits Medicare Part $D$ is a substantial advantage. Drug utilization management techniques such as step therapy and prior authorization may actually save patients out-of-pocket expenses, but monthly premiums, deductibles, and cost sharing add a significant financial burden. A patients' costs for oral oncology drugs can vary widely among Part D plans, and all elements of plan design should be considered prior to choosing a Part D plan. Access to oral oncology drugs may save both Medicare and beneficiaries costs, but seniors do not always pick the plan that would save them the most money. Streamlining Medicare Part D to include fewer plans, fewer options within plan design, and making gap coverage available would lower beneficiaries' out-ofpocket costs.

\section{Document Type}

Thesis

Degree Name

Master of Science (MS) 


\section{Program}

Health Outcomes and Policy Research

\section{Research Advisor}

David K. Solomon, Pharm.D.

\section{Keywords}

Medicare Part D, Out-of- pocket costs, Drug tiers, Prior authorization, Oral oncologic therapies

\section{Subject Categories}

Health and Medical Administration | Health Services Research | Medicine and Health Sciences |

Pharmacoeconomics and Pharmaceutical Economics | Pharmacy and Pharmaceutical Sciences 


\title{
ANALYSIS OF OUT-OF-POCKET EXPENDITURES OF ORAL ONCOLOGICS FOR TENNESSEE RECIPIENTS OF MEDICARE PART D
}

\author{
A Thesis \\ Presented for \\ The Graduate Studies Council \\ The University of Tennessee \\ Health Science Center \\ In Partial Fulfillment \\ Of the Requirements for the Degree \\ Master of Science \\ From The University of Tennessee
}

By

Eve Carolyn Elias

May 2011 
Copyright (C) 2011 by Eve Carolyn Elias.

All rights reserved. 


\section{DEDICATION}

This research is dedicated to my husband Cliff, who continues to support anything I attempt to accomplish. 


\section{ACKNOWLEDGEMENTS}

I would like to acknowledge the members of my thesis committee, Dr. Robert Nolly, Dr. Junling Wang, Dr. Trevor McKibbin, Dr. James Hoffman, Dr. Richard Faris, and in particular my committee chair, Dr. David Solomon. I would also like to thank George Relyea of the University of Memphis and Dr. Grant Somes (posthumous) of the University of Tennessee for their assistance with statistical analysis, and Dr. Katie Suda, my residency director. 


\begin{abstract}
Background: There are few studies that examine patients' costs of oral oncology drugs from Medicare Part D plan providers. These drugs can impose a financial burden to beneficiaries, and, due to their cost, place beneficiaries in the coverage gap in a short period of time. In addition to examining costs, there is little published concerning the potential impact of drug utilization management techniques on access to these drugs in Medicare Part D plans. This study examined the roles of prior authorization, steptherapy, and placement of drugs in higher formulary tiers on patients' out-of-pocket costs, and access to therapy.
\end{abstract}

Methods: A cost analysis of pricing structure data for nine oral oncology drugs from the 48 Medicare Part D stand-alone plans in Tennessee in 2009. Out-of-pocket costs per drug on an annual basis, copayments per claim, monthly premiums, and deductibles as well as an analysis of the time to the coverage gap, and patient expenses beyond the catastrophic limit are examined. This analysis includes a summary of the changes to drug utilization management techniques to these drugs on the plans from 2008 to 2009 and examines their impact on members'out-of-pocket expenses.

Results: Of the one million eligible seniors in Tennessee, only about $43 \%$ were enrolled in a Medicare Part D plan in 2009. There were 48 plans offered in 2009 with a variety of deductibles, premiums, and cost-sharing strategies. For the drugs in the study, imatinib, lenalidomide, sorafenib, erlotinib, dasatinib, sunitinib, vorinostat, nilotinib, and lapatinib, the annual out-of-pocket costs for each drug varied from $\$ 0$ to a maximum of $\$ 1,133$, based on plan design. Bivariate regression analysis showed that monthly premiums, deductibles, and cost-sharing are all precise predictors of out-of-pocket expenses $(\mathrm{p}<.001)$ and demonstrated to what extent each of these parameters are important to out-of-pocket expenses. For every $\$ 1$ increase in monthly premiums, out-ofpocket costs increased by $\$ 14.27$ for imatinib and $\$ 14.29$ for the remainder of the study drugs. A cost sharing increase of $1 \%$ is associated with a $\$ 41.45$ increase in out-ofpocket expenses for imatinib. That same $1 \%$ increase in cost sharing resulted in a $\$ 41.16$ increase in out-of-pocket expenses for the remainder of the study drugs. Annual deductibles provide cost savings to beneficiaries; for every dollar increase there is a significant reduction in annual out-of-pocket expenses of \$1.45. Drug utilization management tools such as prior authorization resulted in cost savings to members for all study drugs except for vorinostat and lapatinib; however, the results were not statistically significant.

Conclusions: There is little doubt that for seniors lacking prescription drug benefits Medicare Part D is a substantial advantage. Drug utilization management techniques such as step therapy and prior authorization may actually save patients out-ofpocket expenses, but monthly premiums, deductibles, and cost sharing add a significant financial burden. A patient's costs for oral oncology drugs can vary widely among Part D plans, and all elements of plan design should be considered prior to choosing a Part D plan. Access to oral oncology drugs may save both Medicare and beneficiaries costs, but 
seniors do not always pick the plan that would save them the most money. Streamlining Medicare Part D to include fewer plans, fewer options within plan design, and making gap coverage available would lower beneficiaries' out-of-pocket costs. 


\section{TABLE OF CONTENTS}

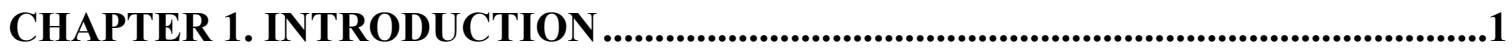

CANCER INCIDENCE AND DEMOGRAPHICS …............................................

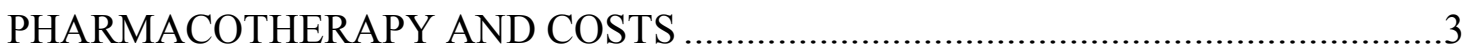

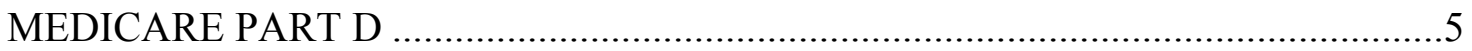

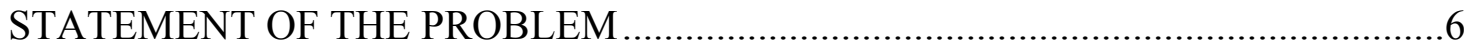

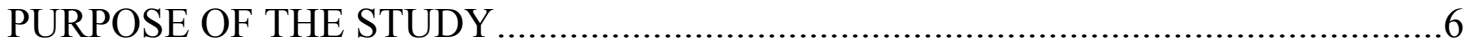

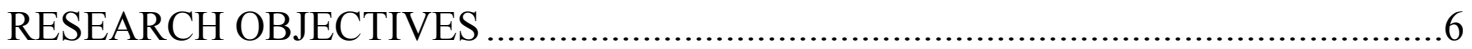

DEFINITION OF KEY TERMS AND CONCEPTS ….........................................

RELEVANCE TO HEALTH POLICY AND PHARMACOECONOMICS .................8

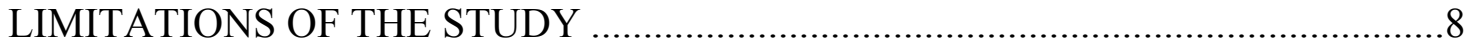

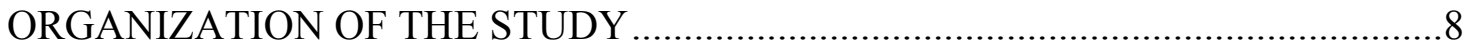

CHAPTER 2. REVIEW OF THE LITERATURE .....................................................11

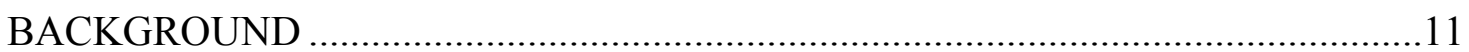

OVERVIEW OF MEDICARE PART D PLANS ................................................... 11

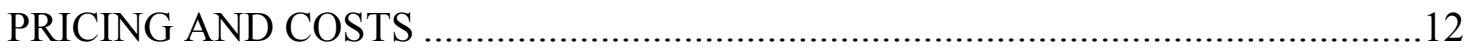

DRUG UTILIZATION MANAGEMENT TECHNIQUES ....................................... 13

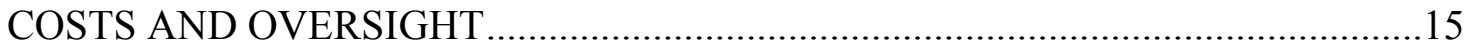

ECONOMIC THEORY AND PATIENT ADHERENCE ….........................................

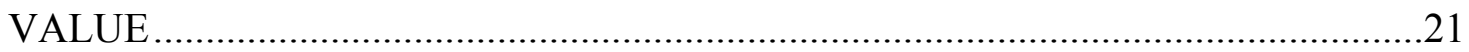

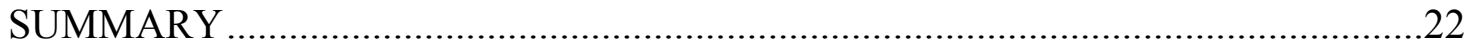

CHAPTER 3. METHODOLOGY ....................................................................24

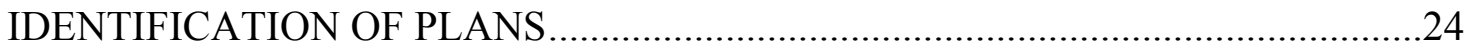

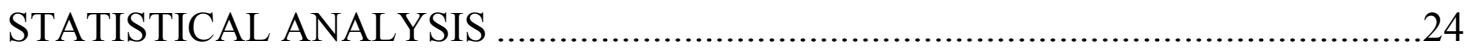

CHAPTER 4. RESULTS...................................................................................27

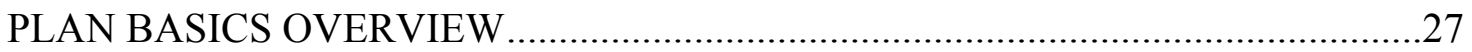

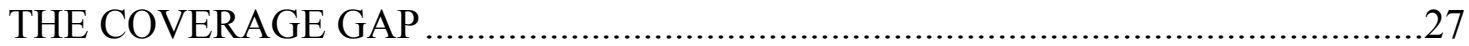

USING REGRESSION TO PREDICT THE INFLUENCE OF PLAN DESIGN ........31

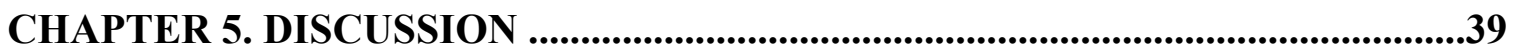

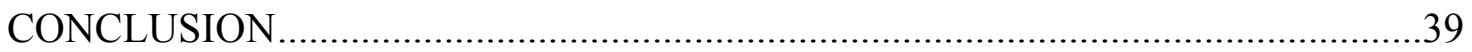

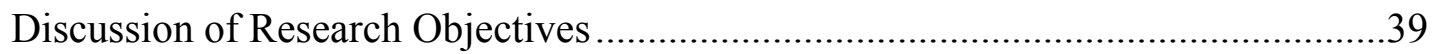

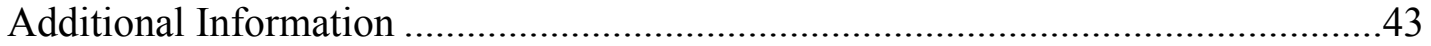

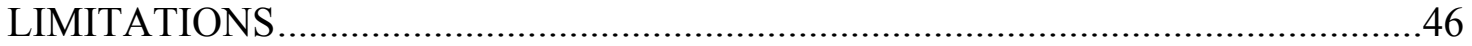

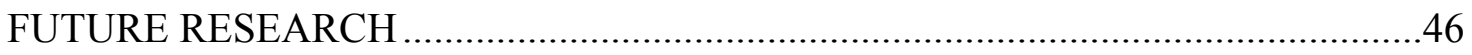

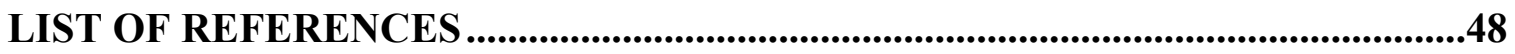

VITA 


\section{LIST OF TABLES}

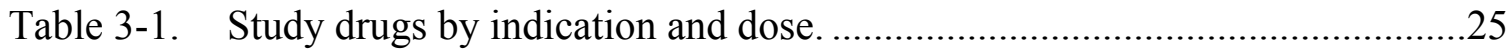

Table 4-1. Basic elements of Medicare Part D plans in Tennessee: 2008 vs. 2009......29

Table 4-2. Drug utilization management strategies used by Part D plans applied to

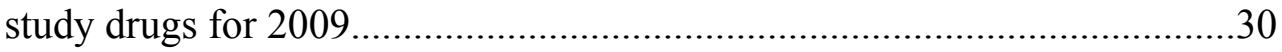

Table 4-3. Bivariate regression equations predicting total out-of-pocket expenses for imatinib

Table 4-4. Bivariate regression equations predicting total out-of-pocket expenses for lenalidomide.

Table 4-5. Bivariate regression equations predicting total out-of-pocket expenses for sorafenib.

Table 4-6. Bivariate regression equations predicting total out-of-pocket expenses for erlotinib

Table 4-7. Bivariate regression equations predicting total out-of-pocket expenses for dasatinib.

Table 4-8. Bivariate regression equations predicting total out-of-pocket expenses for sunitinib.

Table 4-9. Bivariate regression equations predicting total out-of-pocket expenses for vorinostat.

Table 4-10. Bivariate regression equations predicting total out-of-pocket expenses for nilotinib.

Table 4-11. Bivariate regression equations predicting total out-of-pocket expenses for lapatinib

Table 5-1. 2009 Medicare Part D plan design by drug. 


\section{LIST OF FIGURES}

Figure 1-1. Rates of cancer (all types) for persons 65 and older for the years 20002005

Figure 1-2. Projection spend and proportion of spend for specialty drugs in 2005 (left) and 2009 (right).

Figure 2-1. Number of Medicare prescription drug plans using specialty tiers, 20062008.

Figure 2-2. Beneficiary out-of-pocket spending per category..................................18

Figure 4-1. Medicare Part D plan overview for Tennessee. .28

Figure 4-2. Out-of-pocket expenses of various Part D plans related to the doughnut hole.

Figure 4-3. Total annual out-of-pocket cost ranges for study drugs. .32

Figure 5-1. Premium changes from 2008 to 2009 


\section{CHAPTER 1. INTRODUCTION}

Medicare Part D plans establish and maintain a formulary on an ongoing basis. Within these formularies, plans have the flexibility to define different levels of costsharing known as tiers. Plan tiering typically includes generic, preferred, and nonpreferred tiers, with an established amount of cost-sharing associated with each tier. A growing number of plans have added an additional tier for high-cost drugs which is referred to as a specialty tier, where cost-sharing is defined by variable coinsurance payments. These coinsurance rates require that enrollees pay a percentage ranging from $25 \%$ to $50 \%$ of a drug's cost in this tier. CMS established a minimum cost threshold that drugs must meet before plans can place them on a specialty tier; in 2007, the minimum

monthly cost was $\$ 500$, and in 2008 and 2009 the minimum was $\$ 600 .{ }^{1}$ The definition of specialty is not consistent among payers.

Among the most costly agents placed in the specialty tier category are the oral drugs used in cancer treatment. Leukemia, lymphoma, renal cell carcinoma, lung cancer and breast cancer are examples of cancer that have oral therapies available as treatment options. These drugs have extended progression free survival while avoiding toxicities such as nausea, vomiting, myelosuppression and alopecia.

Prior to the arrival of oral oncolytic drugs, many cancers were managed or controlled using intravenous regimens that may slow the progression of the disease, but did not necessarily improve overall survival. However, the oral targeted therapies also have the ability to stop disease progression, and may turn cancer into another chronic disease, much like rheumatoid arthritis.

\section{CANCER INCIDENCE AND DEMOGRAPHICS}

As the population in the U.S. ages, the number of Medicare enrollees is expected to almost double between 2010 and 2030, from approximately 40 million to 70 million. ${ }^{2}$ Cancer diagnoses increase with age, with the potential to devastate and overwhelm the Medicare system.

According to the Surveillance Epidemiology and End Results (SEER) program, cancer rates (per 100,000) have decreased for persons 65 and older for the years 20002005, and are displayed in Figure 1-1. ${ }^{3}$ Incidence rates may be dropping due to increased patient education, better lifestyle choices such as smoking cessation and decreased use of hormone replacement therapy in women. While there is increased utilization of screenings, there may be some inconsistency in the screening practices which would permit many cancers to go undetected.

The most recent data from SEER estimates cancer prevalence in the 65 and older age group to be approximately 5 million. Tennessee has higher than the average national cancer rate for lung cancer (82.2 vs. 66.8) and melanoma (19.8 vs. 18.2), but lower rates 


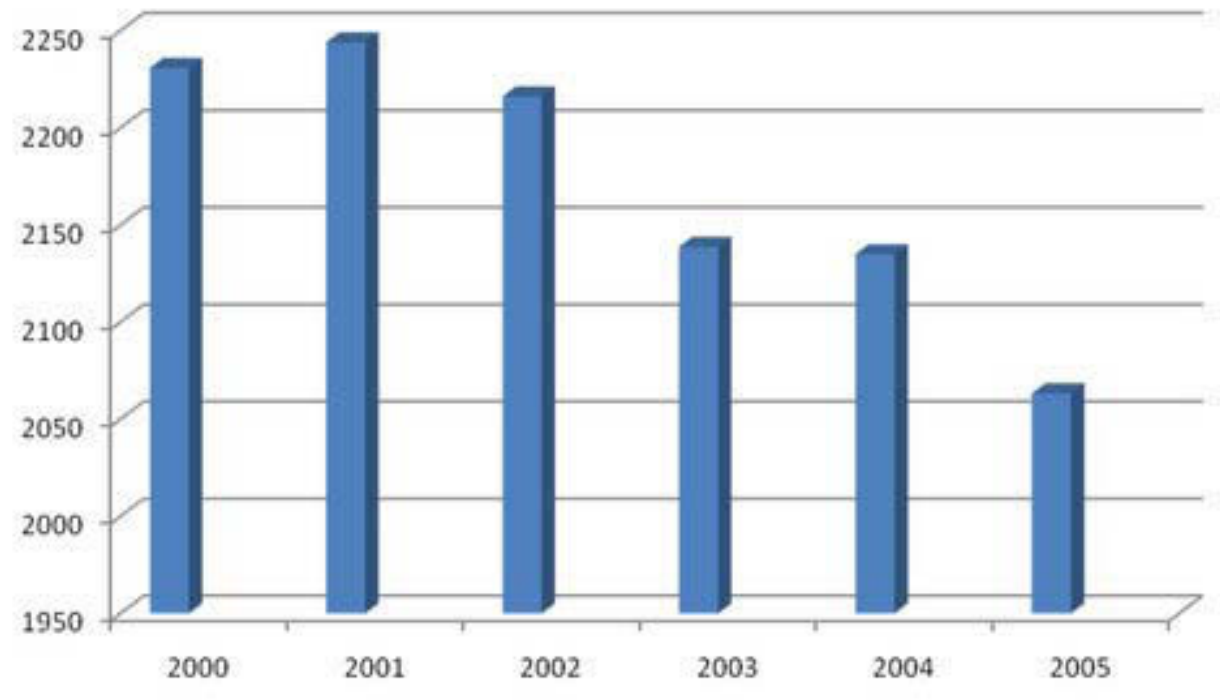

Figure 1-1. Rates of cancer (all types) for persons 65 and older for the years 20002005.

Rates reported as new diagnoses per 100,000 persons. 
for breast (117.2 vs. 119.3) and prostate (141.2 vs.152.6) cancers. Incidence rates are cases per 100,000 population per year.

The Annual Report to the Nation on the Status of Cancer is a collaborative effort by the American Cancer Society, the Centers for Disease Control and Prevention, the National Cancer Institute, and the North American Association of Central Cancer Registries. According to the report published in 2007 (p. 2120 ), "Overall cancer death rates decreased by $2.1 \%$ per year from 2002 through 2004 , nearly twice the annual decrease of $1.1 \%$ per year from 1993 through 2002." It is important to note, though, that many cancers such as chronic myelogenous leukemia are now "managed" long-term as a chronic disease, thereby improving disease-free survival for these conditions. ${ }^{4}$

\section{PHARMACOTHERAPY AND COSTS}

As a percentage of overall drug costs, the specialty drug category continues to grow as a portion of average utilization. Utilization of traditional drugs grew at an average rate of $1.6 \%$ in 2007 . Utilization of specialty drugs increased $3.9 \%$ in 2007 and had increased $14.7 \%$ by the end of $2009 . .^{5}$ Besides introduction of new specialty drugs in 2007, this growth was also driven by expanding indications for many existing specialty drugs.

Cancer drugs, comprising approximately $17 \%$ of overall specialty drug spending in 2007 was exceeded only by spending for autoimmune conditions. ${ }^{5}$ According to the Medco DrugTrend report for 2008, roughly one-third of the drugs in the drug development pipeline are specialty drugs, and $60-70 \%$ of those are oral oncology drugs. ${ }^{5}$

These small molecule inhibitors vary from traditional chemotherapy drugs in a number of ways. First, they are administered orally, as opposed to intravenously. Most of these oral agents are metabolized by Cytochrome P450 enzymes, which may result in multiple drug interactions. The oral therapies may provide treatment options for some patients, such as the elderly with comorbid conditions who may not otherwise be candidates for "traditional" chemotherapy.

For Medicare beneficiaries, the increasing use of oral chemotherapy presents an increasing financial burden as costs for these therapies are shifted from traditional Part B coverage to the newer Part D coverage. Prior to the arrival of Part D, the few oral therapies that were available as well as traditional parenteral chemotherapy were covered under Part B. In designing Part D the decision was made to keep the parenteral therapies under Part B due to their method of delivery and perhaps costs. Introduction of the new oral chemotherapy drugs provide not only an option to parenteral chemotherapy, but in many cases an improvement in progression free survival.

Among the newer oral oncologics, sorafenib and sunitinib are therapies for advanced renal cell carcinoma. Prior to their introduction, treatment options were limited and progression free survival rates were low. Sorafenib is a multikinase inhibitor for 
treatment of advanced kidney cancer, later approved for hepatocellular carcinoma. ${ }^{6}$ Although kidney cancer accounts for only about 3\% of adult cancers, kidney cancer occurs most often in people between the ages of 50 and 70. It affects men almost twice as often as women and, if detected early enough, may be curable surgically. ${ }^{7}$ However, tumors that are advanced (i.e., cannot be surgically removed or have spread to other parts of the body) are difficult to treat. In clinical trials, sorafenib decreased time to tumor progression from 84 days to 167 days ${ }^{7}$ An alternative for patients with advanced renal cell carcinoma is sunitinib. Another tyrosine kinase inhibitor, sunitinib is also approved for gastrointestinal stromal tumors resistant to imatinib. ${ }^{6}$ It is not known at this time if patients may become resistant to sunitinib.

Another recent addition to the oral oncologics is lenalidomide, a thalidomide analog which represents an option from thalidomide for patients with multiple myeloma or myelodysplastic syndrome. ${ }^{6}$ Lenalidomide was originally approved for patients with myelodysplastic syndrome (MDS). ${ }^{8}$ Prior to the introduction of lenalidomide, patients suffering from MDS had to endure frequent blood transfusions due to profound anemia. Lenalidomide reduced transfusion requirements in clinical trials, and some patients became transfusion independent. ${ }^{9}$ The mechanism of action of lenalidomide is not fully understood, but it does possess antineoplastic, immunomodulatory and antiangiogenic properties. $^{8}$ In 2007, FDA approval was obtained for use in multiple myeloma, in place of multiple cytotoxic drugs. ${ }^{6}$

Lapatinib is another new therapy approved for use in combination with capecitabine for use in metastatic breast cancer. A multi-kinase inhibitor, lapatinib is a small molecule drug that is often effective for patients with HER-2 positive breast cancer that are no longer responding to traztuzumab. ${ }^{10}$ When compared to capecitabine therapy alone, lapatinib with capecitabine produced a statistically significant decrease in time to tumor progression. ${ }^{6}$

A number of options are available for Philadelphia chromosome positive chronic leukemia including imatinib, dasatinib and nilotinib. Imatinib was the first oral targeted therapy. It is an oral tyrosine kinase inhibitor that was originally approved for Philadelphia chromosome positive chronic myeloid leukemia. The Philadelphia chromosome is an abnormality of chromosome 22 in which part of chromosome 9 is transferred to it. Imatinib later gained approval for gastrointestinal stromal tumors, hypereosinophilic syndrome, chronic eosinophilic leukemia, aggressive systemic mastocytosis, myelodysplastic syndrome, and myeloproliferative disease. ${ }^{11}$

Dasatinib is an oral tyrosine kinase inhibitor for chronic myeloid leukemia and Philadelphia chromosome positive acute lymphoblastic leukemia. Tyrosine kinase inhibitors interfere with cell communication, thereby inhibiting tumor growth. Patients taking dasatinib have commonly failed or are intolerant to prior therapy. ${ }^{6}$

Nilotinib is an alternative kinase inhibitor for chronic phase and accelerated phase Philadelphia chromosome positive chronic myelogenous leukemia. Bone marrow cells that contain the Philadelphia chromosome are often found in chronic myelogenous 
leukemia. In clinical trials, patients taking nilotinib, at 3 months 30 of 31 patients achieved complete cytogenetic response, with all 20 evaluable patients at 6 months and all 11 at 12 months, reaching complete cytogenetic response. ${ }^{12}$

Erlotinib is another tyrosine kinase inhibitor that was initially approved for use in non-small cell lung cancer and later approved for use in locally advanced, unresectable or metastatic pancreatic cancer. ${ }^{13}$ In randomized, placebo-controlled trials, erlotinib prolonged survival in patients who progressed following one or two prior chemotherapy regimens. ${ }^{14}$

Vorinostat is used for cutaneous T-cell lymphoma. Vorinostat is a histone deacetylase (HDAC) inhibitor approved for cutaneous T-cell lymphoma. ${ }^{15}$ A new class of antineoplastics, HDAC inhibitors target a key step in the removal of acetyl from lysine. The resulting inhibition of tumor growth is believed to be due to drug-induced accumulation of acetylated proteins. ${ }^{15}$

\section{MEDICARE PART D}

After many years of discussion, Medicare-approved private insurers were granted the option to offer prescription drug benefits under the Medicare Prescription Drug, Improvement, and Modernization Act of 2003. Various proposals for a Medicare drug benefits plan had been debated since the Clinton administration. In January 2006, Medicare Part D began as the outpatient prescription drug benefit for Medicare recipients. By early May, approximately 31 million beneficiaries were enrolled in a Medicare Part D drug plan. ${ }^{16}$ The stand-alone plans are administered through a wide variety of plans and compete on the basis of premiums, benefits structure and pharmacy networks. In these plans, Medicare subsidizes approximately $75 \%$ of premiums and provides additional subsidies for lower income beneficiaries.

The standard Medicare Part D benefit for 2009 included the following:

- A plan deductible of $\$ 295$;

- Coverage for $75 \%$ of allowable drug expenses up to a benefit limit of $\$ 2,700$;

- Beneficiary pays all costs in the coverage gap;

- A $\$ 4,350$ catastrophic limit on true out-of-pocket spending;

- $5 \%$ coinsurance rate for drug spending above the catastrophic limit. ${ }^{17}$

Individual plans often offer alternative pricing structures where the deductibles may be lowered and employ the use of tiers for various drugs in the plan. As long as the benefits criteria meet actuarial equivalence, these parameters may be varied.

The amount of spending above $\$ 2,700$ up to the catastrophic limit is known as the "doughnut hole" or coverage gap. In this range, there are no benefits except the plan's discounted price for prescription drugs.

Medicare Part D plans in Tennessee have a variety of pricing structures, and many 
have no gap coverage. This can translate into thousands of dollars out-of pocket for seniors who have limited incomes after retirement, and may be struggling with other expenses as well. Medicare out-of-pocket costs can vary by state of residence as well. With so much variability in plan pricing structures and out-of-pocket expenses, patients may stop treatment or stop therapy for other chronic conditions, ultimately leading to greater expenses through increased use of emergency and hospital care.

Therefore, it is important to examine the varying pricing structures of Medicare Part D plans in Tennessee and what effect these pricing structures have on out-of-pocket expenditures for oral oncology drugs.

\section{STATEMENT OF THE PROBLEM}

There are few studies that com pare the co st to beneficiarie s of oral oncology drugs using publicly available information to examine pricing structure. In add ition to examining costs, drug utilization m anagement techniques such as prior authorization and step therapy will b e examined. This study wi 11 measure the specific impact of oral oncology drugs on Medicare beneficiaries out-o f-pocket spending through the variety of Part D plans offered in Tennessee.

\section{PURPOSE OF THE STUDY}

The primary goal of the study was to outline costs for Medicare enrollees using oral oncology drugs. For the purpose of the study, nine oral cancer drugs were examined. These drugs were chosen due to the potentially significant impact on a Medicare Part D beneficiary's out-of-pocket expenses. Specialty tier eligible pharmaceuticals are a rapidly growing component of drug spending. An increasing portion of that spending is for oral oncology drugs. The objective was a cost analysis of oral cancer therapies under Medicare Part D plans in Tennessee. The expected findings from examination of the data included dollars spent per drug by members for Medicare Part D plans in Tennessee, and examination of changes to pricing structures from 2008 to 2009. Examining benefits design such as prior authorization, step therapy, disease management programs, and tiered copayments would illustrate the presumed advantages of making oral oncology drugs accessible to patients. Health plan drug formularies face increasing pressures to include new therapies while keeping per-member-per month costs to a minimum. With numerous oral oncology drugs in late stage development, and a variety of pricing structures for Medicare Part D benefits, beneficiaries can use this information to forecast future expenditures.

\section{RESEARCH OBJECTIVES}

1. Conduct a cost analysis of nine oral cancer therapies under Medicare Part D plans in Tennessee. 
2. Examine pricing structure trends from 2008 to 2009 and their impact on beneficiaries' out-of-pocket expenses for nine oral cancer drugs.

3. Analyze the relationship between drug utilization management techniques used by Medicare Part D plans and access to medications under CMS guidelines.

\section{DEFINITION OF KEY TERMS AND CONCEPTS}

Access: For the purpose of this study, access refers to a patient's ability to obtain needed medications, due to both availability as well as affordability.

CMS: The Center for Medicare and Medicaid Services that oversees the various Medicare Part D plans offered.

Cost-sharing: Cost-sharing refers to the drug cost s assigned to the patient, also known as a copayment.

Deductible: An amount of money that must be paid by th e patient be fore the insurance plan's coverage begins.

Drug utilization management: A number of tools used by insurance plans in an attempt to contro 1 costs, and $\mathrm{m}$ ay include premiums, deductibles, cost sharing, prior authorization and step therapy.

Formulary: An insurance plan's formulary is a set of drugs that the plan will pay for at different levels, or tiers of cost-sharing.

Medicare Part D: The voluntary outpatient drug benefit subsidized by Medicare. Plans have a variety of pricing structures and services available. Plans compete for enrollees on the basis of these pricing structures, as long as benefits meet certain tests of actuarial equivalence.

Oral oncology drugs: Cancer drugs that block the growth and spread of cancer by interfering with specific molecules involved in carcinogenesis and tumor growth. For the purposes of the study they will be defined by the following: 1) oral oncology drugs, 2) cost a minimum of $\$ 6,000$ per year and and 3) no generic equivalents available

Pharmacy Benefits Management (PBM): A third party administrator of prescription drug programs, primarily responsible for processing and paying prescription drug claims. They also are responsible for developing and maintaining the formulary, contracting with pharmacies, and negotiating discounts and rebates with drug manufacturers.

Premium: The amount of money paid by the patient for insurance coverage. 
Specialty Pharmacies: Supply specialty drugs to patients and operate either independently or through a pharmacy benefits management company (PBM).

\section{RELEVANCE TO HEALTH POLICY AND PHARMACOECONOMICS}

In addition to the constant research, development and approval process of new specialty drugs, utilization for existing specialty tier eligible drugs, including oral oncology drugs, has increased steadily, and projections show a much larger portion of the overall spending for prescriptions coming from specialty drugs. Figure 1-2 shows projected spending for specialty drugs in 2009 based on claims data from 2005 . $^{18}$

Besides the increasing number of specialty drugs entering the marketplace, the costs of specialty drugs is growing at twice the pace of other outpatient drug therapy. ${ }^{18}$ Strategies to involve patients in cost-sharing include prior authorizations, utilization review, tiered copays, disease management programs and the use of specialty pharmacies. Drug costs for treatments in this class range from a minimum of approximately $\$ 6,000$ per year to over $\$ 250,000$ per year.

The potential impact of specialty drug use could be devastating to both payers and patients. Examining trends in Medicare Part D benefits structure for oral oncology drugs, and their future impact as drugs enter late-stage development is crucial to make policy as well as benefit design and budget decisions.

\section{LIMITATIONS OF THE STUDY}

This analysis is intended to be descriptive, focusing on direct financial effects of oral oncology drugs on beneficiary out-of-pocket expenses, and whether access is impeded by the use of formulary management tools. Cost-effectiveness and cost per outcome are beyond the scope of this study.

The study is limited to Medicare Part D "stand-alone" plans and does not include Medicare Plus plans or members with dual eligibility in another plan.

\section{ORGANIZATION OF THE STUDY}

Presentation of the study is organized into five chapters. Chapter 1 is the introductory chapter, which explains the importance of the subject. Chapter 2 contains a review of the literature, which includes all relevant published information relating to the subject of specialty drugs, in particular oral oncology drugs, pharmacy benefits management organizations, healthcare benefits administration, economics, with a focus on oral oncology drugs. Chapter 3 is a description of the methodology including study design, data and data analysis used to collect the relevant information for the study. Chapter 4 presents of the results of the data analysis. Chapter 5 discusses the findings 


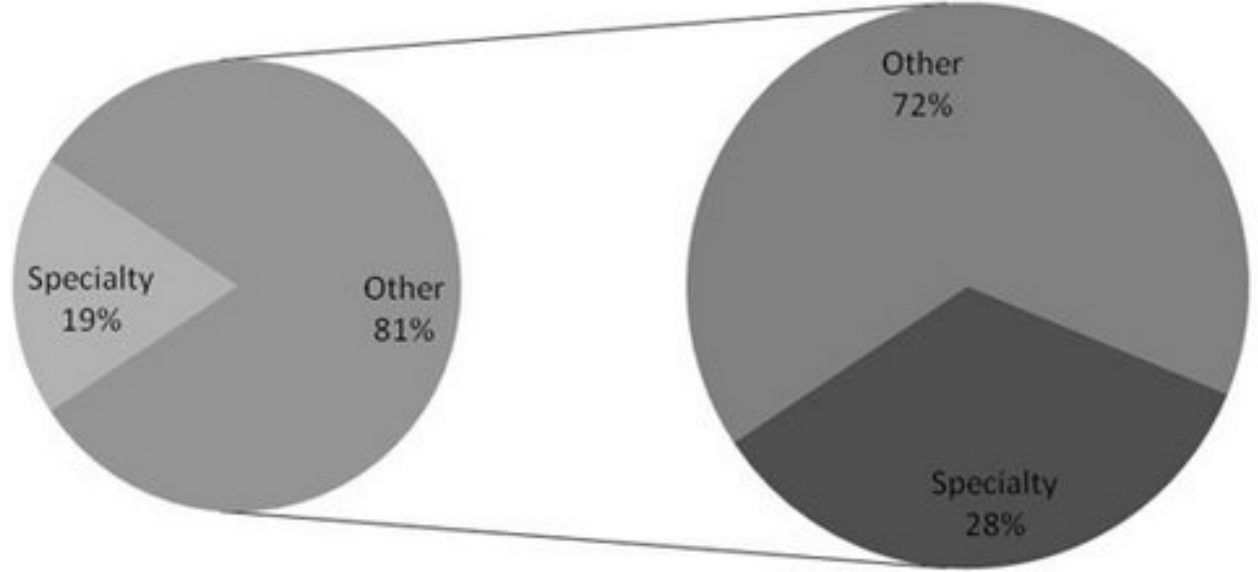

Figure 1-2. Projection spend and proportion of spend for specialty drugs in 2005 (left) and 2009 (right). 
and conclusions that may be drawn from the study, as well as identifying further questions for future research. 


\section{CHAPTER 2. REVIEW OF THE LITERATURE}

\section{BACKGROUND}

This chapter discusses Medicare Part D plan design, drug pricing and costs, drug utilization management, economic theory and beneficiary response as well as value as it pertains to both pharmaceutical and medical services used by Medicare beneficiaries.

\section{OVERVIEW OF MEDICARE PART D PLANS}

All Medicare Part D plans maintain a drug formulary, or a list of medications available under the plan, as well as their cost-sharing category, also known as a tier. When used appropriately, formularies provide lower cost alternatives to patients without compromising care. Although similarities occur, Part D plans are able to choose their formulary structure and choose the tier assignment for each drug on their formulary. Generally, higher tiers are reserved for the newest brand-name drugs as well as those with the highest costs or specific conditions for use.

All Part D plan formularies must include "all or substantially all drugs" in "six classes of clinical concern." The six protected classes include antidepressants, antipsychotics, antiretrovirals, antineoplastics, immunosuppressants, and anticonvulsants. The purpose of this policy was to ensure that patients already receiving these medications would not be discouraged or denied from continuing treatment secondary to drug utilization management techniques such as placing the drugs in a higher tier structure, or requiring prior authorization. Under the CMS regulatory guidance, drugs in these classes can be subject to "tiering" or placement in higher tier, but may not be subject to step therapy or prior authorization, except at the time of therapy initiation. ${ }^{19}$ Without these drug utilization management tools to control utilization and costs, plan administrators must rely on negotiation techniques such as rebates to control costs in the program.

There are a few exceptions to the CMS guidelines on protected drug classes. A prescription drug plan may exclude gefitinib (antineoplastic), fosphenytoin (anticonvulsant), and either escitalopram or citalopram (antidepressant) from their formularies. For newly approved drugs launched after April 16, 2007 in the protected classes, there is a requirement that a prescription drug plan's pharmacy and therapeutics committee make an expedited decision concerning formulary placement. This equates to a 90 day timeframe rather than a 180 day timeframe for drugs not in one of the protected classes. It furthermore stipulates that the plan subsidize $75 \%$ of costs between the deductible and initial coverage limit. Another provision allows for plans to exclude or remove from their formulary any drug with a black-box warning, ${ }^{20}$ which would apply to lapatinib, lenalidomide and nilotinib. Additionally, plans can request to remove drugs from their formulary, can request to place drugs on a less preferred tier, can impose midyear formulary changes and can impose conditions for reimbursement. 


\section{PRICING AND COSTS}

The Medicare Part D system itself puts plans at risk for the cost of the drug benefit. $^{21}$ Therefore, plans have an incentive to control costs and prevent adverse selection. Adverse selection occurs when a plan attracts members who incur higher costs, however the plan is not able to charge higher premiums. If a disproportionate number of these members are enrolled, over time, the plan may stop offering the coverage, and leave only plans with minimal coverage. As a result, Part D plans may maintain formularies with the costliest drugs in the highest tiers and charge premiums that may discourage higher cost members from enrolling.

Nearly 750,000 Medicare enrollees were diagnosed with cancer in $2008 .^{22}$ There are an estimated 5 million Medicare enrollees living with cancer. This places a heavy economic burden on the Part D system in the case of the newer oral therapies which are not covered in Part B. Information obtained from the Medicare Current Beneficiary Survey revealed that prevalent case spending for cancer was $\$ 16,854$ with patient out-ofpocket expenses of $\$ 2,753$, and incident case spending of $\$ 26,345$ with patient out-ofpocket expenses of $\$ 4,062 .{ }^{23}$

Physician practices administering parenteral chemotherapy make as much as $80 \%$ of their revenue from dispensing and administration. ${ }^{24}$ They receive no revenue for dispensing or administering oral chemotherapy and monitoring becomes more of a challenge when patients are responsible for increased cost sharing and adherence. These are relatively new issues in respect to oncology, where patients who were typically shielded from the costs of therapy are now exposed to the cost of therapy and a decision of whether the treatment is worth the cost must be made.

Since the inception of Medicare Part D, physicians have been deluged with questions concerning the "best" Part D plan from patients. This is especially true in oncology practices, where patients are acutely aware of the costs of medications prescribed to them. In order to outline some of the pricing disparity that occurs in pricing for oncology drugs in Part D plans, the editors of Community Oncology analyzed the pricing of seven oral drugs within three communities of different size. The authors discovered that there is significant pricing variation for these seven drugs within the same market. For sunitinib, the price range varied by as much as $12 \%$, while pricing for thalidomide varied by $571 \%$, or a mean cost of approximately $\$ 6,289 .{ }^{25}$ Although this study was performed in the earlier days of the Part D program, the Medicare 2006 plans, it points out the potential hazards that can be encountered by a population that is vulnerable and often uninformed about all aspects of plan design. Although voluntary enrollment in Part D plans was greater than many anticipated for the new public program, a survey indicated that many beneficiaries were confused by their enrollment options. ${ }^{26}$ $73 \%$ of people ages 65 and older felt that the Medicare prescription drug benefit was too complicated, along with $91 \%$ of pharmacists and $92 \%$ of doctors. ${ }^{27}$

In a policy forum sponsored by the American Cancer Society's nonprofit advocacy group, ACS CAN, and Avalere Health, a public policy and business strategy 
advisory company, new data were released that showed that cancer patients enrolled in Medicare Part D plans are increasingly paying more for cancer therapies under Part D plans. Reasons outlined in the report include the shifting of cancer drugs to higher formulary tiers, and the increasing use of prior authorization. This research also shows that for stand-alone Medicare Part D plans, there is a trend to shift expensive oral oncology drugs to a higher tier. In $2006,36 \%$ of plans required a prior authorization for imatinib, this grew to $84 \%$ of plans in $2008 .^{28}$

\section{DRUG UTILIZATION MANAGEMENT TECHNIQUES}

Specialty tiers have important implications for cancer patients enrolled in Medicare Part D. In particular, many plans have lowered the standard deductible while raising specialty drugs to a higher tier, increasing cost-sharing, and making the plan more attractive on the surface. Medicare prescription drug plans using specialty tiers have grown from 4 of 21 plans in 2006 to 21 of 41 plans using specialty tiers in 2008. Figure 2-1 shows the total number of Medicare Part D plans using specialty tiers.

In addition, coinsurance, also known as cost-sharing rates have steadily increased from $19 \%$ of plans using $33 \%$ coinsurance in 2006 to $51 \%$ of plans using $33 \%$ coinsurance for specialty tier drugs, including oral oncolytics in 2008. In most instances, cost-sharing for specialty tiers is limited to $25 \%$ according to CMS guidance, but CMS allows higher cost-sharing if it offset by a lower deductible. ${ }^{29}$

David L. Knowlton, a member of a nonprofit that provides financial assistance to patients with life-threatening illnesses theorizes that the original intention of copayments and coinsurance was to limit unnecessary and inappropriate utilization of drugs. The result has been a shift from inappropriate utilization to increased costs to beneficiaries. He further states that health plans have found that increasing copays and other techniques such as prior authorization are the only ways to gain leverage. ${ }^{30}$ The end result is simply a shifting of costs over to the patient.

In any case, this translates into higher out-of-pocket costs for those enrollees using oral oncology drugs. This could result in a costly situation for enrollees who are prescribed a specialty tier eligible drug during a period when they are not allowed to change plans. ${ }^{29}$ On the other hand, plans that place oral oncology drugs on a tier with low cost sharing may attract a disproportionate number of enrollees using specialty drugs leading to adverse selection. This may be an important aspect in the future, as it may influence physician prescribing habits and patient adherence.

According to a report by MedPAC, an advisory commission on Medicare payment issues, the percentage of Medicare Part D enrollees in plans that used specialty tiers rose from $63 \%$ in 2006 to $74 \%$ in 2007 . This trend, along with more drugs being placed in specialty tiers lead to higher out-of pocket expenses for Part D enrollees. It should be noted that unlisted drugs may be available through the nonformulary request process, which may vary in difficulty between plans. Other utilization management tools 


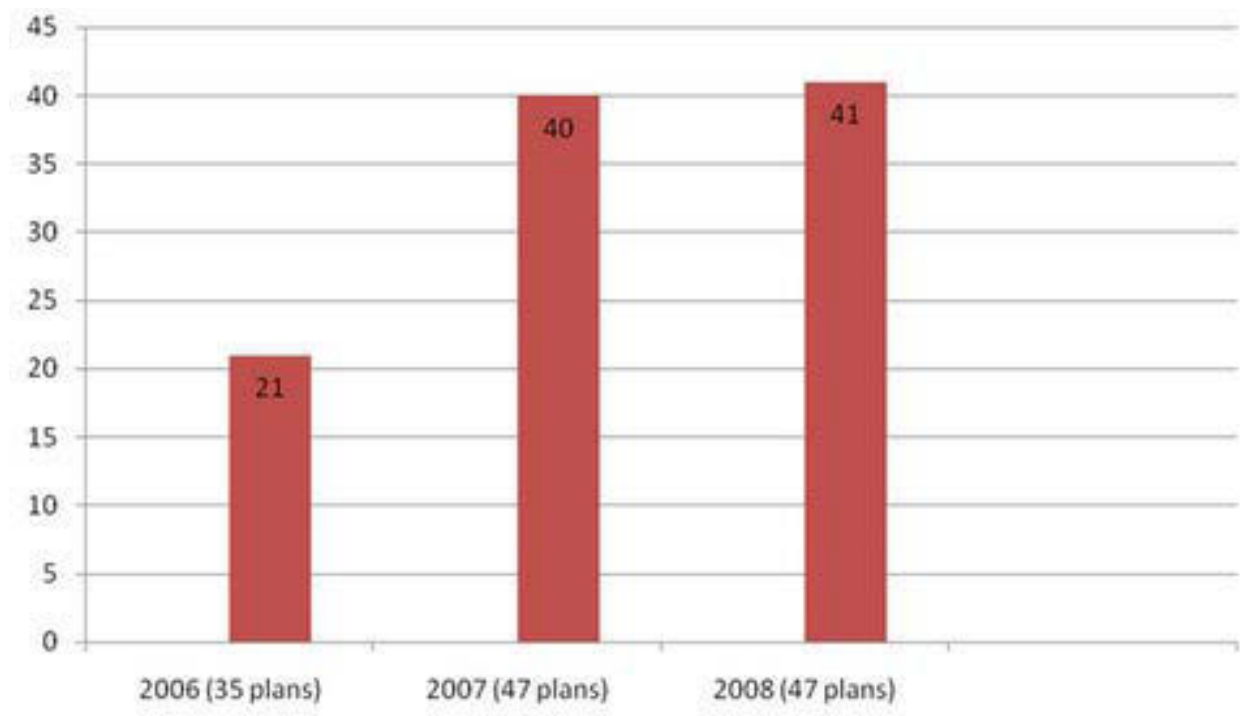

Figure 2-1. Number of Medicare prescription drug plans using specialty tiers, 2006-2008. 
outlined in the MedPAC report for 2007 are 12\% of drugs on the formularies are subject to quantity limits, $1 \%$ are subject to step therapy, and $8 \%$ are reported to have some requirement for prior authorization. Summary statistics from this report show that $18 \%$ of drugs are subject to some type of utilization management. The report further asserts that the number of drugs maintained on a plan's formulary does not represent access to medications. Access to drugs through prior authorization can often influence prescribing habits of physicians, and alter their choice of medications for their patients. ${ }^{31}$ The extent to which this occurs with oncology drugs is not known.

Curtiss et al. performed a demonstration of spending and utilization trends for 11 selected oral oncology drugs using a database from a PBM of approximately 500,000 members and found that plan spending tripled in this one category during the timeframe of the study. The data showed a linear increase of $0.27 \%$ to $0.73 \%$ in total PBM spending for oral oncology drugs over the 2002-2006 time period. ${ }^{32}$ Much of the reason for this is the fact that five of the drugs (lenalidomide, sorafenib, erlotinib, dasatinib and sunitinib ) were approved during this time frame. Sunitinib, dasatinib and lenalidomide were all approved in 2006, so their contribution to overall spending may not be fully recognized. Increased approvals as well as expanded indications would lead to additional utilization in the years since the study was published. Lenalidomide, a thalidomide analog was originally approved in combination with dexamethasone for treatment of multiple myeloma, was later approved for a second indication, myelodysplastic syndrome, at an increased price per patient of about 35\%. Curtiss cites criticism by some Wall Street analysts of excessive pricing and its potential financial impact on Medicare and Medicaid.

Large PBMs, such as Medco, with approximately 65 million members that serve Medicare Part D enrollees closely monitor the use of oral oncologics, especially those with some type of formulary restriction, such as prior authorization. Since oral agents represent only a small portion of a patient's treatment for cancer compared with several courses of intravenous chemotherapy, the price of the oral drugs seems to be a reasonable trade-off by possibly avoiding adverse effects of treatment such as febrile neutropenia and thrombosis. A retrospective claims database analysis of mean total medical costs for patients with renal cell carcinoma compared three treatment modalities. Patients receiving bevacizumab incurred mean total monthly costs of $\$ 13,351$. Patients using sorafenib and sunitinib respectively incurred costs of $\$ 6,998$ and $\$ 8,213$. ${ }^{33}$ The use of oral drugs avoid the nursing time, cost of intravenous access, pumps, physician charges, and they are associated with fewer treatment related side-effects such as dehydration, nausea and infections that result in hospitalizations.

\section{COSTS AND OVERSIGHT}

Medicare's involvement in the cost of cancer care affects both the overall economics and incentive structures pertaining to cancer care. There are three key elements pertinent to overall costs. The first is the fact that Medicare is involved in financing all aspects of cancer care, from diagnostic procedures, laboratory procedures, 
physicians' services to drugs. ${ }^{34}$ However, these coverage decisions may vary by locale based on available evidence and whether the determination is made through local contractors or by Medicare itself. Cost containment efforts by plan sponsors typically involve negotiating prices for drugs where a number of alternatives exist, however there is little leverage to negotiate prices for drugs in this category. In a report from the GAO, the average negotiated price for imatinib (Gleevec) across a sample of plans increased by 46 percent between 2006 and 2009, from about $\$ 31,200$ per year to about $\$ 45,500$ per year. $^{35}$

The second element involves Medicare's overhaul of an outmoded payment system that aims to reduce costs in clinical situations where alternative therapy may produce similar outcomes. ${ }^{34}$ In the past, intravenous chemotherapy could be purchased for far less than the reimbursement provided by Medicare. A change in payment structure to physicians where it is no longer possible to include chemotherapy as large portion of revenues will help to lower costs. One of the major shifts in this structure is the increasing use of oral chemotherapy drugs, and lowering reimbursements for infused chemotherapies.

The third element is Medicare's focus on transparency and quality. Groups such as the Cancer Quality Alliance, a collection of physicians, patients, payers and other federal agencies are reviewing approaches to measuring and improving quality in cancer care. In a demonstration project in 2006, claims data were used as a measure of quality. Oncologists could voluntarily submit information to Medicare about symptoms experienced during chemotherapy, and in turn billing codes were checked to see if clinical practice guidelines, such as those from the National Comprehensive Cancer Network (NCCN) were followed on treatment. Reasons for not following practice guidelines included either patient or physician preference, or participation in a clinical trial. The data suggest that not all care is evidence based, and there is some suspicion that excess costs may be due to frequent testing and additional chemotherapy and radiation beyond what is supported by the evidence. The author stresses the importance of integrating information on costs and outcomes to physicians and patients, in order to facilitate shared decision making and transparency for the patient. ${ }^{34}$

As K.T. Adams explains, the strategy taken by one large PBM is an attempt to encourage "appropriate use" by physicians. The author states that evidence should dictate the drug's use, and monitor that patients and their physicians follow FDA and manufacturers' guidelines in the use of these drugs. ${ }^{36}$ CMS will reimburse for a medication if it is listed in specific compendia for off-label use in a type of cancer. Most private payers use multiple compendia. The most well recognized sources of information are the NCCN Drugs and Biologics Compendium and DrugDex, both of which are now being used as sources for coverage decisions under Medicare. Changes to CMS's lists of compendia may have influence on large private payers as they review their own coverage policies.

A compelling argument for increased oversight of Medicare Part D benefits plans is presented in a study by Cohen et al. from the Tufts Center for the Study of Drug Development that gathered information from 36 prescription Medicare drug plans, and 
focused specifically on the six protected classes of drugs: anticonvulsants, antidepressants, antineoplastics, antipsychotics, antiretrovirals, and immunosuppressants in the year 2007. The authors identified 201 unique molecular entities in the six protected classes in order to address the following questions:

- The percentage of drugs included on-plan formularies

- The average price of on-formulary versus nonformulary drugs

- Comparing the prices of drugs that all plans have on-formulary with prices of drugs that at least one plan does not have on-formulary

- If placed on-formulary, in which cost-share tier

- How much the patient pays out-of-pocket between the deductible and the point at which the "doughnut hole" is reached

- The percentage of covered drugs with conditions of reimbursement

- Whether the presence of a black-box warning influenced the decision to place a drug on-formulary or impose conditions of reimbursement.

Among the results, the authors found the average percentage of drugs on all plan formularies to be $83 \%$. None of the plans studied covered all of the 201 drugs, even as non-formulary. The median co-payment was $\$ 38$ per prescription with a range from $\$ 2$ to $\$ 930$. The class with the highest out-of pocket spending was antineoplastics. ${ }^{37}$ Figure 2-2 shows out-of-pocket spending for each of the classes.

Average out-of-pocket costs in the study sample were $28 \%$ between deductible and the initial coverage limit, and $55 \%$ of the plans implemented cost-sharing that is higher than the $25 \%$ cost-sharing rule. In the study year of $2007,15 \%$ of the 201 drugs required prior authorization and $18 \%$ had at least one condition of reimbursement, whether step therapy, quantity limits or any other restriction. ${ }^{37}$ The overall conclusion is that none of the plans complied with the "all or substantially all" clauses in the CMS guidelines concerning coverage of these drug classes. Furthermore, more than half of the plans imposed cost-sharing that is higher than $25 \%$ per prescription. The use of prior authorization underscores the potential to reduce patients' access to drugs through timeconsuming and laborious requirements for documentation and a restrictive appeals process. Conversely, some physicians may avoid prescribing certain drugs due to this burdensome task of requiring prior authorization. Additional studies may determine if additional oversight by CMS is warranted to ensure that the protected classes studied are readily available as outlined in the guidelines. ${ }^{20}$

A study of access to oncology drugs in Medicare Part D plans by Bowman, et.al. analyzed Part D plans' coverage of a defined set of oncology drugs chosen by reviewing listings in the approved compendia. Drugs for the study were chosen on their frequency of presence on Part D plan formularies, and included the targeted therapies erlotinib and imatinib. The authors further described variations in cost-sharing and access to the drugs under Medicare Part D plans. Their analysis showed that Part D plan formularies included $75 \%$ of oncology drugs identified in the compendia, with generics more frequently covered than brand-name entities. Prior authorization was found to be used more frequently with newer, brand-name drugs, and no step therapy requirements were 


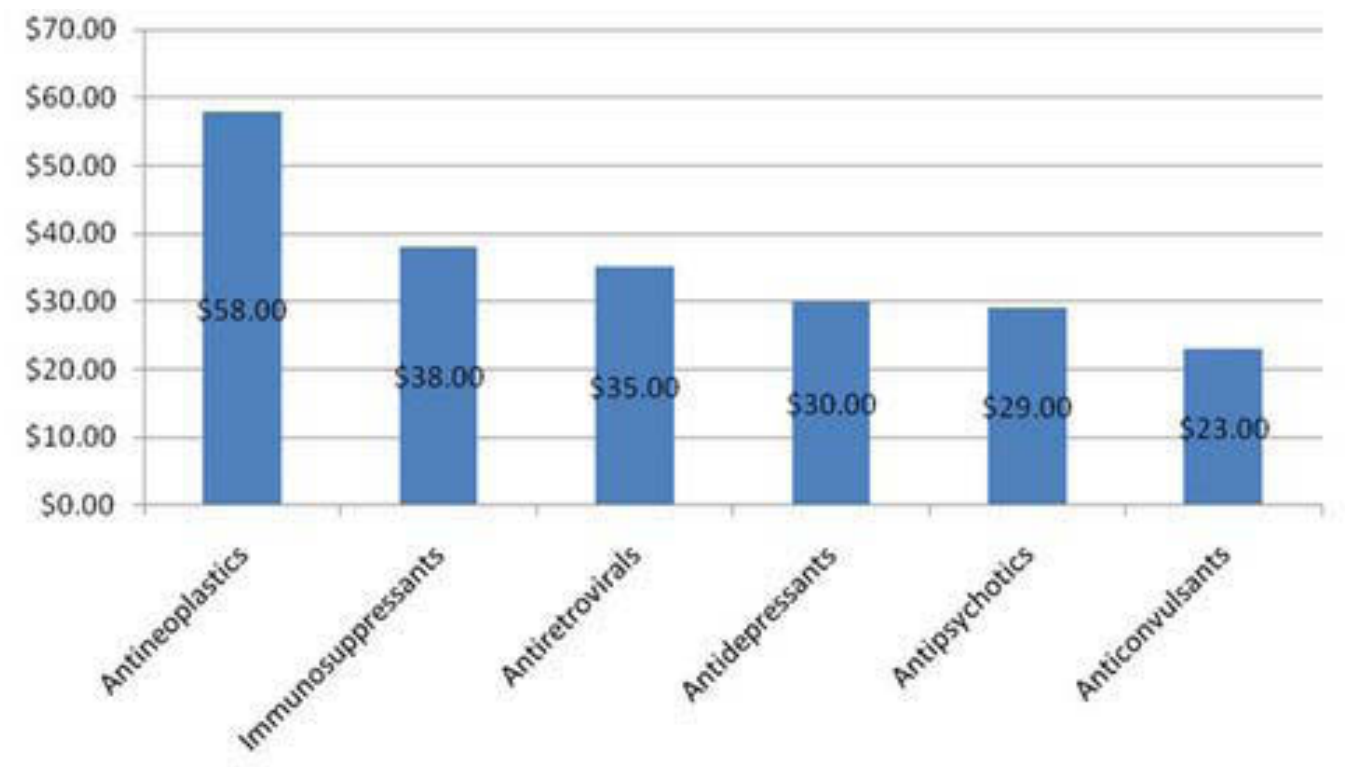

Figure 2-2. Beneficiary out-of-pocket spending per category. 
found. Cost-sharing strategies varied among plans, but most plans covered brand-name drugs in the higher tiers than generics. It was found that prior authorization was applied more frequently to brand-name drugs over generics. ${ }^{38}$ Although there is no conclusive evidence, the authors point out that the use of prior authorization may impede access and cause delays to treatment, which may affect patient outcomes. A limitation identified by the authors states that since premium data were not available for review, it was not possible to analyze whether plans with higher premiums may offer better coverage for cancer therapies.

Part D plans may employ a number of strategies to manage costs and utilization. Coverage decisions are made on an individual plan basis, with the guidance of evidencebased resources. The Medicare Coverage Database (MCD) contains all National Coverage Determinations (NCDs) and Local Coverage Determinations (LCDs), local policy articles, and proposed NCD decisions. ${ }^{39}$ The National Coverage Determination process is used in some cases to dictate which patients and for what indications a service may be covered. In the case of chemotherapy, which is one of the six protected drug classes, the use of the drug compendia may be implemented or in some cases a local coverage determination can be made.

\section{ECONOMIC THEORY AND PATIENT ADHERENCE}

There is little debate over the economic theory that increased out-of-pocket spending leads to lower consumption of healthcare expenses. The elasticity of demand theory gauges the extent to which consumers alter their consumption behavior when prices change. This was demonstrated in the Rand Health Insurance Experiment, ${ }^{40}$ which has been duplicated in a number of studies to prove its validity. For increasing prices of prescription drugs in particular, this phenomenon can present in a number of ways using economic theory. First, changes in consumption as prices increase to move patients up the demand curve, the optimal level will be reached where a reduction in consumption results. Second, if patients or their physicians find an acceptable, lower cost therapy, they are likely to consume reduced amounts of costly prescription drugs. Lastly, for drugs that are perceived as high-cost with low value, the demand for these therapies would decrease, conversely patients would be relatively price insensitive for drugs considered to be of high value, such as life-sustaining drugs, given that patients have adequate information concerning benefits and outcomes. ${ }^{34}$

A comparison of clinical and economic outcomes of Medicare + Choice beneficiaries in 2003 by Hsu, et al. showed the consequences of limits on prescription drug benefits. The study compared consumption of drugs subject to capping, rates of use of medical services, such as hospitalizations, emergency department visits, and physician office visits, to patients whose benefits were not capped. Odds ratios were calculated to show the relationship between adherence and long-term physiological outcomes, such as increased blood pressure, increased serum lipids, and increased hemoglobin A1C levels. Differences in monthly drug utilization between the groups showed that patients whose benefits were capped were greater in the months after the cap than in earlier months. The 
data were similar for adherence rates. Drugs used for the study included antihypertensive drugs, lipid-lowering drugs, and antidiabetic drugs. In all three drug classes selected those whose benefits were capped were more likely to be nonadherent, OR $1.30 ; 95 \% \mathrm{CI}$ $(1.23-1.38){ }^{41}$ This suggests negative clinical as well as economic consequences for beneficiaries when drug benefits are capped. These patients had higher rates of nonelective hospitalizations, visits to the emergency department, and even death. Although the cost-sharing arrangements in this study are not identical to prescription drug coverage under Medicare Part D, the relationship between increasing costs and decreased medication adherence can be extrapolated to Medicare Part D. The authors concluded the potential savings in drug costs from the implementation of caps are offset by increases in the costs of hospitalization and emergency room visits.

Polinski et al. (2009) examined annual out-of-pocket costs for biologic disease modifying anti-rheumatic drugs (DMARDS) use in Medicare Part D enrollees. ${ }^{42}$ The authors compared "stand-alone" plan with Medicare Advantage plan enrollees annual out of pocket costs. The study showed that those enrolled in stand-alone plans had higher out-of-pocket costs than those in advantage plans, and that shifting the financial burden of high cost medications from the plan to the patient resulted in worse outcomes for both the patient and Medicare. These patients may delay therapy due to high copayments or discontinue therapy when the coverage gap ensues, ultimately resulting in more out-ofpocket expenses from decreased compliance. For Medicare, this translates into increased costs as well for caring for non-compliant patients in emergent situations. ${ }^{42}$

Another study that mirrors this theory appeared in April 2005. Stuart, et al. used a similar design to the Hsu study using Medicare enrollees in HMO plans with prescription drug benefits caps. The authors state that their study will provide policymakers with empirical evidence concerning Medicare Part D beneficiaries' spending patterns and the effects of coverage gaps. Data for the study were taken from the 1998-2000 Medicare Current Beneficiary Survey (MCBS), which is conducted by CMS to collect healthcare services and prescription drug information. They evaluated the effect of prescription drug coverage gaps for beneficiaries with chronic diseases, namely, diabetes, chronic lung disease and mental illness. Strong predictors of prescription drug spending were age, sex, race, poverty and health status. The authors constructed models to simulate the impact of coverage gaps in Medicare Part D, and found that for patients with any of the chronic diseases previously mentioned the impact was considerable. Any savings that can be realized under Medicare Part D are not equally distributed, and the model simulations show that Medicare beneficiaries react to interruptions in prescription drug coverage by reducing spending and that impact is greater for those with chronic disease states. $^{43}$

Athough the orginal intent of Medicare Part D was to increase access to medications for beneficiaries, variations in utilization management and the coverage gap may have a deleterious effect on patients with chronic conditions. Studies across various therapeutic settings have suggested that increased out-of pocket expenses can affect a beneficiary's adherence to drug therapy. The array of Part D plans is confusing to 
patients and physicians alike, and physicians typically aren't aware of what type of coverage patients have when considering treatment options. ${ }^{44}$

\section{VALUE}

A survey of 25 medical and 20 pharmacy directors from managed care organizations around the nation as well as 5 pharmacy directors from PBMs evaluated perceptions of the value offered by erlotinib and sunitinib compared to bevacizumab in relation to median survival and cost. $48 \%$ of respondents believed that 1 month of treatment with bevacizumab for metastatic colon cancer offered a good value, with $28 \%$ believing that true for erlotinib for non-small cell lung cancer (NSCLC) and 32\% for sunitinib for renal cell carcinoma (RCC). When surveyed on the role of treatment costs influencing coverage decisions regarding reimbursement policy, only $15 \%$ responded that costs definitely influence their decision currently, and $13 \%$ believed that costs probably influenced their decision. Eighty percent of the respondents agreed that in the future costs will play a larger decision concerning which therapies to cover without restrictions. $^{45}$

There are a number of initiatives aimed at improving the quality of care under the Medicare system for cancer care including pay-for-performance, preferred provider organization arrangements, national Medicare cancer registries, predictive modeling and quality measures. An example of this type model was developed at Geisinger Health System for cardiac bypass services that bundles Medicare payments to evidence-based practice episodes of care. For CABG services, the model includes a flat fee plus $50 \%$ of the "historically expected cost of management of complications" incurred for the next 90 days. In addition, Geisinger offered financial guarantees to payers both prior to and after the procedure. This model not only saved money for payers, but significantly improved patient outcomes as well. The savings produced by this intervention more than paid for the cost of implementation. ${ }^{46}$

The premise of value-based insurance design is providing high benefits relative to costs. An example of a high benefit service is colorectal screening beginning at age 50, or reducing or eliminating copayments for essential medications that prevent significant morbidity and mortality. The effect of eliminating or reducing copayments on medication adherence was evaluated at a large Fortune 500 company for employee beneficiaries with diabetes or vascular disease. Separate cohorts were created to study copayment reductions for statins and clopidogrel. Regression modeling was used to determine if the policy influenced medication adherence immediately or over a 24 month period. For statin users there was no significant change in adherence levels immediately, but the rate of change in subsequent months increased significantly. The clopidogrel group's results were similar. ${ }^{47}$ This analysis demonstrated that reducing or eliminating copayments leads to improved adherence, and would support adoption of this strategy by third-party payers to increase medication adherence. In addition, value based insurance design may be used to identify ideal patients to participate in disease management programs and receive waivers for copayments. 
A commentary by Lee and Emanuel discusses the use of innovative treatments, such as targeted and specialty drugs that have turned many fatal diseases into chronic ones. $^{28}$ The issue is not the increase in the patients' time to progression or survival, but the costs of these drugs, and how best to pay for them. The authors discuss the revision that insurers have made to their formulary structures, such as placement of costly, brandname drugs on a higher tier with an increased cost share to the beneficiary. Often, these drugs are placed in a tier 4 status, which is considered by most insurers to be what is termed "coinsurance." In this scenario, beneficiaries pay a percentage of drug costs rather than a fixed copay, which for many of the newer biologics and specialty drugs, can run into thousands of dollars per month, exceeding what most patients budgets can bear. Tier 4 systems are present in about $86 \%$ of Medicare drug plans. The issues with tier 4 is that it focuses strictly on costs, and ignores effectiveness as well as cost-effectiveness. An example used in the article is that of trastuzumab (Herceptin). Trastuzumab, which is approved for adjuvant treatment of breast cancer can cure 4-6 women for every 100 who are treated, at a cost of about $\$ 55,000$ per patient treated. Bevicizumab (Avastin) slows progression of metastatic breast cancer with no overall effect on survival. ${ }^{48}$ The two drugs each cost about $\$ 55,000$ per course of treatment and are subject to the same conditions of coverage. The authors question if this is ethically, clinically or economically sensible. The approach of transferring costs through means of capitation, tiered copayments, or coinsurance began in the 1990s with limited success. Since only $10 \%$ of patients account for about $70 \%$ of healthcare spending, there is a limit to how much cost shifting can occur to these patients. If providers can agree that costeffectiveness has a role in coverage decisions, then physicians can incorporate these interventions into treatment guidelines, ultimately identifying which patients will benefit from these interventions, and that improved efficiency is a core value of today's practice of medicine.

\section{SUMMARY}

Weingart et al. discuss the challenges and shifting roles of physicians, pharmacists, patients and caregivers in the use of oral chemotherapy. ${ }^{24}$ Oral chemotherapy requires increased education time for patients from pharmacists and nurses which is generally uncompensated care. Adherence is another issue that must be addressed when considering a patient for oral chemotherapy. In the case of Medicare Part D beneficiaries, a lack of social support, communication issues or type of regimen may be associated with reduced adherence.

Financing as it relates to the increasing use of oral chemotherapy presents many challenges to patients and payers with patients bearing the increased cost burden for oral chemotherapy drugs. Although oral chemotherapy may represent an improvement in value in many respects, such as hospitalizations related to side effects, many of these drugs have been placed in the highest formulary tiers, resulting in increased out-of-pocket expenses for patients. Drug utilization management techniques that were originally designed to prevent inappropriate use has resulted in increased costs and reduced 
adherence. Medicare Part D patients face significant cost sharing for oral oncology drugs, which may ultimately lead to decreased adherence and increased inpatient admissions. 


\section{CHAPTER 3. METHODOLOGY}

The research objectives outlined in Chapter 1 were as follows: 1) conduct a cost analysis of nine targeted oral cancer therapies under Medicare Part D plans in Tennessee, 2) examine pricing structure trends from 2008 to 2009 and their impact on beneficiaries' out-of-pocket expenses for nine targeted oral cancer drugs, and 3) analyze the relationship between drug utilization $\mathrm{m}$ anagement techniques used by Medicare Part D plans and access to medications under CMS guidelines.

The drugs for the study were identified based on the following characteristics as outlined in Chapter 1: 1) oral oncology drugs, 2) cost a minimum of $\$ 6,000$ per year and and 3) no generic equivalents available. Table 3-1 shows the drugs with the indication and dose used in calculating pricing for the study.

\section{IDENTIFICATION OF PLANS}

Medicare Part D plans for the state of Tennessee were identified through the use of the Google internet search using the terms "Medicare Part D plans,"and "Tennessee." The website chosen for this information was www.medicare-partd.com. MedicarePartD.com is designed by the Q1 group, "as a neutral site to objectively educate seniors, Medicare beneficiaries, advocates, agents, and members of the general public who are interested in Medicare Part D prescription drug plans." 49 The website listed each plan available in the state of Tennessee along with information on deductibles, monthly premiums, cost-sharing strategies, and medication management tools such as prior authorization. For the year 2009, there were 48 stand-alone Part D plans in Tennessee, with a variety of cost-sharing strategies. There was also limited information available for 2008 stand-alone plans in Tennessee.

\section{STATISTICAL ANALYSIS}

A Microsoft ${ }^{\circledR}$ Excel (Redmond, WA) spreadsheet was created to capture individual plan information on each of the nine drugs in the study. Parameters included for 2009 were: 1) monthly drug costs, 2) monthly premiums, 3) annual deductible, 4) drug tier, 5) gap coverage, and 6) prior authorization. From these figures a number of equations were created to calculate beneficiaries' out-of-pocket expenses including total annual costs (Eq. 3-1), beneficiaries' costs before entering the doughnut hole (Eq. 3-2), beneficiaries' costs in the doughnut hole (Eq. 3-3), beneficiaries' costs above the catastrophic threshold (Eq. 3-4) and beneficiaries' annual total out-of-pocket costs (Eq. $3-5)$.

$$
\text { Annual drug costs }=\text { Monthly drug costs } * 12
$$

Costs prior to entering doughnut hole $=(2700 *$ cost sharing $\%)+$ deductible 
Table 3-1. Study drugs by indication and dose.

\begin{tabular}{|c|c|c|}
\hline $\begin{array}{l}\text { Drug- Generic } \\
\text { (Brand) }\end{array}$ & $\begin{array}{l}\text { Indication Basis for Dosing } \\
\text { Used in Study }\end{array}$ & Dose/Frequency \\
\hline Imatinib (Gleevec) ${ }^{11}$ & $\begin{array}{l}\text { Philadelphia chromosome } \\
\text { positive chronic myeloid } \\
\text { leukemia }\end{array}$ & $400 \mathrm{mg} /$ day \\
\hline $\begin{array}{l}\text { Lenalidomide } \\
\text { (Revlimid) }^{8}\end{array}$ & Multiple myeloma & $25 \mathrm{mg} /$ day \\
\hline Sorafenib (Nexavar) ${ }^{7}$ & Advanced renal cell carcinoma & $400 \mathrm{mg} / \mathrm{bid}$ \\
\hline Erlotinib (Tarceva) ${ }^{13}$ & Non-small cell lung cancer & $150 \mathrm{mg} /$ day \\
\hline Dasatinib (Sprycel) ${ }^{50}$ & Chronic myeloid leukemia & $100 \mathrm{mg} /$ day \\
\hline Sunitinib (Sutent) ${ }^{51}$ & Advanced renal cell carcinoma & $50 \mathrm{mg} /$ day \\
\hline Vorinostat (Zolinza) ${ }^{15}$ & Cutaneous T-cell lymphoma & $400 \mathrm{mg} /$ day \\
\hline Nilotinib (Tasigna) $^{12}$ & $\begin{array}{l}\text { Accelerated phase Philadelphia } \\
\text { chromosome positive chronic } \\
\text { myelogenous leukemia. }\end{array}$ & $\begin{array}{l}300 \text { or } 400 \\
\mathrm{mg} / \text { day }\end{array}$ \\
\hline Lapatinib (Tykerb) ${ }^{10}$ & Advanced breast cancer & $1,250 \mathrm{mg} /$ day \\
\hline
\end{tabular}


Costs in the doughnut hole $=4350-[2700 *(1$-cost sharing $)]$

Costs above catastrophic threshold $=($ Total annual costs -4350$) * 0.05$ (Eq. $3-4)$

Total annual out-of-pocket costs $=$ costs above catastrophic threshold + costs in doughnut hole $+($ monthly premium $* 12)$

Monthly drug costs were derived based on the original FDA approval for a specific indication and based on normal dosing parameters for that indication. This information was located in the individual drugs' prescribing information, which was then verified in a second source, either Micromedex ${ }^{52}$ or the American Hospital Formulary Service (AHFS) Drug Information ${ }^{53}$ reference. Costs were obtained from The Red Book $^{54}$ using average wholesale price (AWP) for a thirty day supply of each medication.

An analytic model was used to evaluate the impact of monthly premiums, deductibles, cost sharing and prior authorization on out-of-pocket costs. Bivariate regression analysis was used to predict the significance of each of the aforementioned parameters on patients' out-of-pocket expenses. The calculated regression coefficient predicts to what degree each parameter affect out-of-pocket expenses. These regression models are tested using SAS Program 9.2, ${ }^{55}$ as well as the association of predicted probabilities and responses, also known as "c" or the number of concordant pairs.

Comparison was made between 2008 and 2009 plan design on the basis of monthly premiums, deductibles, cost sharing, and prior authorization. Mean deductible and monthly premium for 2008 and 2009 were calculated and compared using a t-test.

Descriptive statistics were used to describe the pricing and costs of all drugs in the study as well as deductibles, premiums and price sharing data for the plans in 2009. Comparisons were made between 2008 and 2009 for prior authorization. Further analysis describes the presence of plans charging the full deductible allowable under CMS guidelines in addition to cost sharing over $33 \%$, and the relationship between monthly premiums above the median and total out-of-pocket costs. 


\section{CHAPTER 4. RESULTS}

In 2009 there were over 1 million seniors in Tennessee eligible for Medicare Part D. Of that number, only $43.4 \%$ (approximately 442,000) were enrolled in a Medicare Part D plan, a slight reduction from $44.7 \%$ or 445,000 in $2008{ }^{56}$ Figure $4-1$ demonstrates features of Medicare Part D plans in Tennessee.

\section{PLAN BASICS OVERVIEW}

A comparison of basic elements of Medicare Part D plans in Tennessee in 2008 and 2008 is shown in Table 4-1. The number of plans decreased from 2008 to 2009, from 55 to 48 , and average premiums increased in 2009 by $13.9 \%$. The standard maximum deductible for 2008 was \$275 and \$295 in 2009, and the percentage of plans charging the maximum decreased slightly, while more plans charged at least a partial deductible and slightly more plans charged no deductible in 2009. All plans in both years used tiered cost sharing ranging from $25 \%$ to $70 \%$ in 2008 , and $25 \%$ to $50 \%$ in 2009 .

Forty-one plans in 2009 used a four tier cost-sharing design with a mixture of copayments (for lower tiers) and coinsurance for drugs in higher tiers. Copayments ranged from as little as $\$ 0$ for Tier 1 drugs to $\$ 90$ for Tier 3 drugs. Coinsurance is used in forty-seven plans for higher tiers, usually Tier 3 and above. Only one of the plans use only coinsurance regardless of the tier.

Table 4-2 shows the drug utilization management strategies applied to drugs in the study in 2009. Most of the oral oncology drugs included required prior authorization. Quantity limits of 30 days supply are applied to approximately one-third of the study drugs, which is consistent with drugs that require prior authorization. Step therapy is applied to two of the study drugs, dasatinib (used in $12.5 \%$ of plans) and nilotinib (used in $18.8 \%$ of plans). In both cases the patient must be intolerant or resistant to therapy with imatinib to obtain the drug through the means of prior authorization.

\section{THE COVERAGE GAP}

Plan design contributes to overall out-of-pocket spending both prior to entering the doughnut hole and while in the doughnut hole. Beneficiaries normally enter the doughnut hole when drug expenses reach $\$ 2,700$, and leave when expenses reach $\$ 4,350$. However, these are not the same as out-of-pocket expenses, which can vary greatly. Differences in deductibles and cost-sharing lead to this variation. For the plans in the study, the costs before entering the doughnut hole are shown in Figure 4-2.

Gap coverage for the doughnut hole is available for only $22.9 \%$ of the 48 plans available in Tennessee, and even with gap coverage, only generic drugs are covered. For the drugs in this study, there are no generics available at this time. 


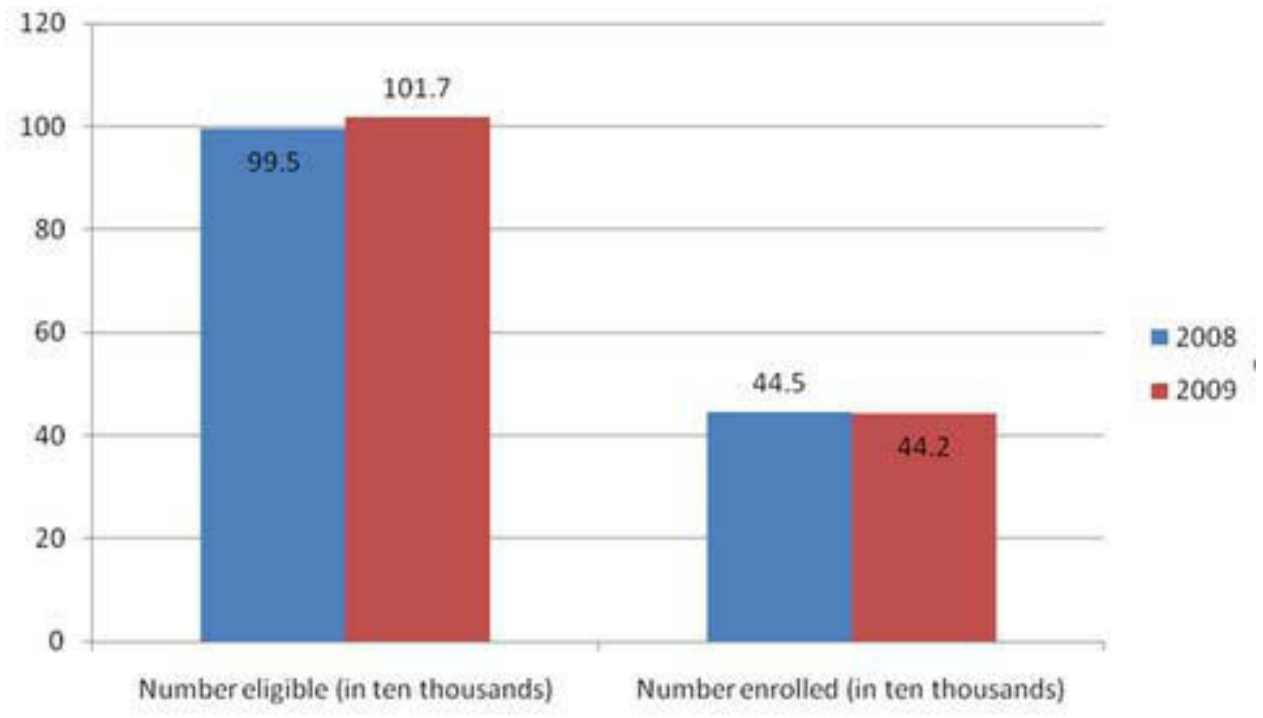

Figure 4-1. Medicare Part D plans overview for Tennessee. 
Table 4-1. Basic elements of Medicare Part D plans in Tennessee: 2008 vs. 2009.

\begin{tabular}{lcc}
\hline Part D Plan Element & $\mathbf{2 0 0 8}(\mathbf{n}=\mathbf{5 5})$ & $\mathbf{2 0 0 9}(\mathbf{n}=\mathbf{4 8})$ \\
\hline Average premium & $\$ 39.26$ & $\$ 44.73$ \\
Maximum & $\$ 98.00$ & $\$ 100.70$ \\
Minimum & $\$ 17.60$ & $\$ 17.60$ \\
Deductible amount & & \\
$\quad$ Maximum & & $29.2 \%$ \\
Partial & $33.3 \%$ & $12.5 \%$ \\
No deductible & $57 \%$ & $58.3 \%$ \\
Uses tiered cost & $100 \%$ & $100 \%$ \\
sharing & $12.7 \%$ & \\
Three tier cost sharing & $81.8 \%$ & $12.5 \%$ \\
Four tier cost sharing & & $85.4 \%$ \\
Coinsurance use & $85.5 \%$ & \\
Some coinsurance & $14.5 \%$ & $85.4 \%$ \\
All coinsurance & $25 \%$ & $14.6 \%$ \\
Minimum coinsurance & $70 \%$ & $25 \%$ \\
Maximum coinsurance & & $50 \%$ \\
\hline
\end{tabular}

${ }^{\mathrm{a}}$ Maximum deductible for 2008 was \$275; it was \$295 in 2009. 
Table 4-2. Drug utilization management strategies used by Part D plans applied to study drugs for 2009.

\begin{tabular}{lccc}
\hline Name of Drug & $\begin{array}{c}\text { Prior Authorization } \\
(\mathbf{n})\end{array}$ & $\begin{array}{c}\text { Quantity Limits } \\
(\mathbf{n})\end{array}$ & $\begin{array}{c}\text { Step Therapy } \\
(\mathbf{n})\end{array}$ \\
\hline Imatinib & $79.6 \%(38)$ & $29.2 \%(14)$ & 0 \\
Lenalidomide & $83.4 \%(40)$ & $35.4 \%(17)$ & 0 \\
Sorafenib & $70.8 \%(34)$ & $37.5 \%(18)$ & 0 \\
Erlotinib & $70.8 \%(34)$ & $35.4 \%(17)$ & 0 \\
Dasatinib & $58.4 \%(28)$ & $35.4 \%(17)$ & $12.5 \%(6)$ \\
Sunitinib & $70.8 \%(34)$ & $35.4 \%(17)$ & 0 \\
Vorinostat & $58.4 \%(28)$ & $35.4 \%(17)$ & 0 \\
Nilotinib & $68.7 \%(33)$ & $35.4 \%(17)$ & $18.8 \%(9)$ \\
Lapatinib & $25 \%(12)$ & $35.4 \%(17)$ & 0 \\
\hline
\end{tabular}

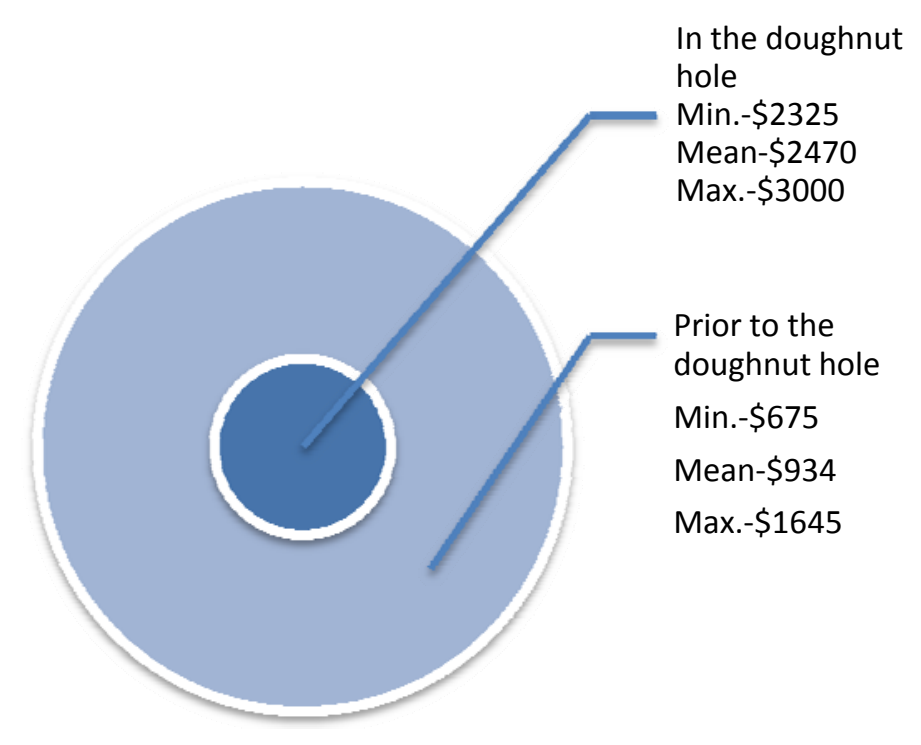

Figure 4-2. Out-of-pocket expenses of various Part D plans related to the doughnut hole. 
Expenses that exceed $\$ 4,350$ per calendar year are considered "catastrophic coverage." When a beneficiary's true out-of-pocket expenses exceed $\$ 4,350$ in a calendar year, the total drug cost is then calculated at $5 \%$ of total costs, regardless of plan design.

Total annual out-of-pocket costs for each study drug are shown in Figure 4-3, using minimum, mean, and maximum pricing from the various 48 available plans. Although the costs for each drug vary, the range of out-of-pocket costs for each drug are the same, due to plan design, resulting in a $\$ 1,133$ variation for each drug.

\section{USING REGRESSION TO PREDICT THE INFLUENCE OF PLAN DESIGN}

Variations in out-of-pocket costs are the result of the effects of differences in the plan design including monthly premiums, deductibles and cost sharing. In this study, 48 plans were reviewed and their out of pocket cost expenses were captured for each of the nine study drugs. In addition, monthly premiums, cost sharing percentage, deductible costs, and prior authorization were measured for each plan. In order to better assess these parameters, the following bivariate regression equations shown in Table 4-3 were performed to predict the influence of these factors individually on out-of-pocket expenses.

From the regression results, the parameter most strongly associated with out-ofpocket expenses is monthly premiums, R-square $81.58 \%$, followed by cost sharing, deductibles and prior authorization. For every $\$ 1$ increase in monthly premium, annual out-of-pocket expenses increase by $\$ 14.29(\mathrm{p},<.001)$. When evaluated the mean of monthly premiums, this parameter adds $\$ 639.33$ to the adjusted mean annual out-ofpocket expenses.

Analysis of deductibles shows that for every dollar increase there is a significant reduction in annual out-of-pocket expenses of \$1.45. Evaluated at average annual deductible of $\$ 114.70$, out-of-pocket spending is reduced by approximately $\$ 165.70$ from the adjusted mean out-of-pocket expenses.

Cost sharing is also a good predictor of out-of-pocket expenses with R-square $48.34 \%$, and every $1 \%$ increase in cost sharing is associated with a $\$ 41.45$ increase in out-of-pocket expenses for imatinib. Evaluated at the mean, a 30.35\% cost sharing plan results in a $\$ 1,258$ increase to the adjusted mean out-of-pocket expenses.

Prior authorization resulted in an average cost reduction of $\$ 78.15$ for imatinib, however this was not statistically significant.

Tables 4-4 through 4-11 show similar results for each drug on out-of-pocket expenses, with exceptions noted. 


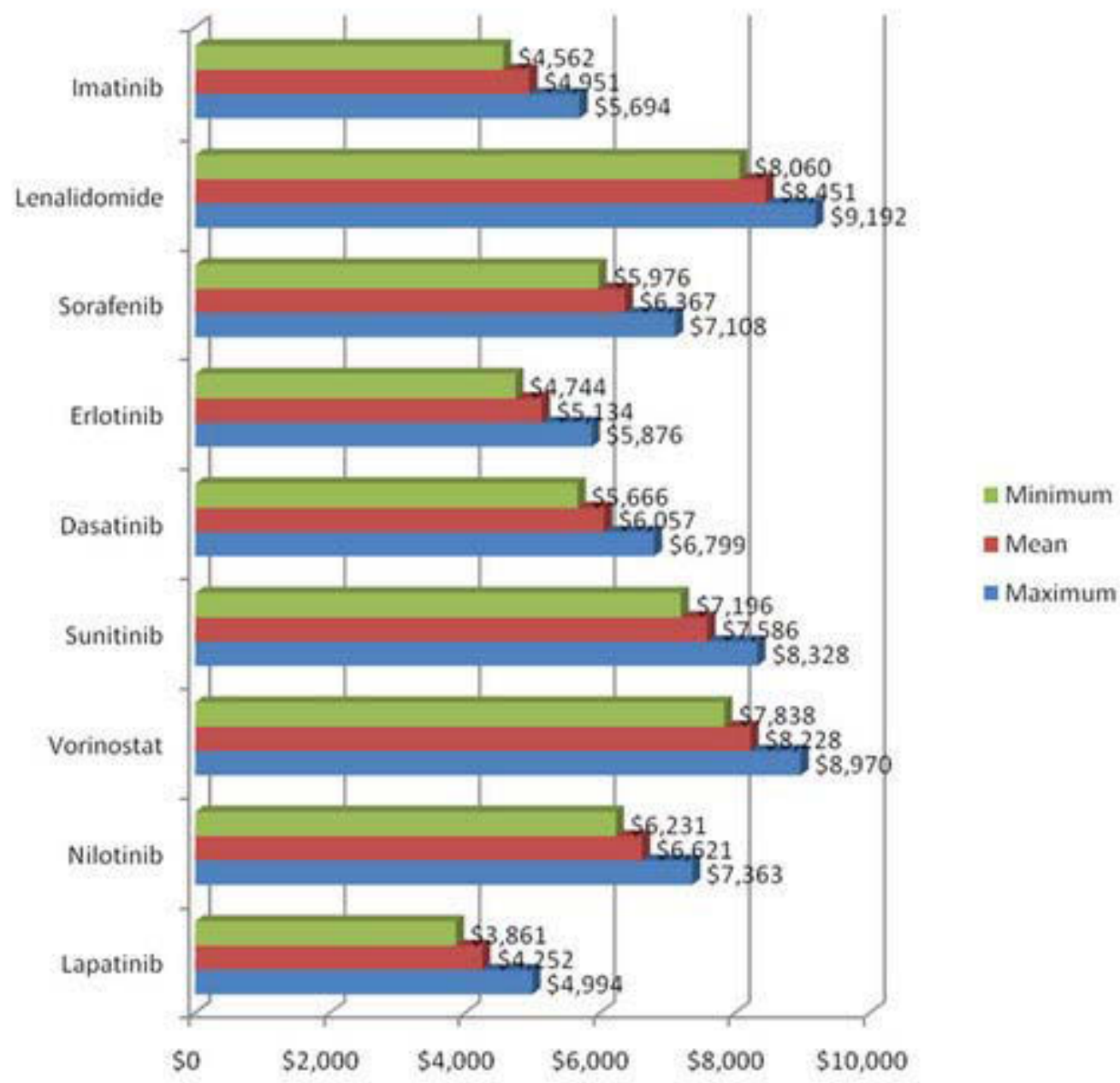

Figure 4-3. Total annual out-of-pocket cost ranges for study drugs. 
Table 4-3. Bivariate regression equations predicting total out-of-pocket expenses for imatinib.

\begin{tabular}{lclcc}
\hline Equation (Predictor) & Intercept (Sig) & $\begin{array}{l}\text { Regression } \\
\text { Coefficient }(\boldsymbol{p})\end{array}$ & $\begin{array}{l}\text { Model } \\
\text { F-ratio** }\end{array}$ & $\begin{array}{l}\text { R-square } \\
(\mathbf{\%})\end{array}$ \\
\hline $\begin{array}{l}\text { Monthly premiums } \\
\text { 2009 }\end{array}$ & $4311.71(<.001)$ & $14.29(<.001)$ & 203.74 & 81.58 \\
Deductible 2009 & $5116.09(<.001)$ & $-1.45(<.001)$ & 30.01 & 39.49 \\
Cost sharing 2009 (\%) & $3692.87(<.001)$ & $41.45(<.001)$ & 43.05 & 48.34 \\
Prior authorization & 5012.86 & $-78.15(.48)$ & 0.50 & 01.07 \\
2009: Yes(1) vs. No(0) & & & & \\
\hline
\end{tabular}

*With 1 and 46 degrees of freedom. Model significance is the same as regression coefficient significance.

Table 4-4. Bivariate regression equations predicting total out-of-pocket expenses for lenalidomide.

\begin{tabular}{lllll}
\hline Equation (Predictor) & Intercept (Sig) & $\begin{array}{l}\text { Regression } \\
\text { Coefficient (p) }\end{array}$ & $\begin{array}{l}\text { Model } \\
\text { F-ratio** }\end{array}$ & $\begin{array}{l}\text { R-square } \\
(\%)\end{array}$ \\
\hline $\begin{array}{l}\text { Monthly premiums } \\
\text { 2009 }\end{array}$ & $7812.32(<.001)$ & $14.27(<.001)$ & 200.28 & 81.32 \\
$\begin{array}{l}\text { Deductible 2009 } \\
\begin{array}{l}\text { Cost sharing 2009 } \\
\text { (\%) }\end{array}\end{array}$ & $8616.68(<.001)$ & $-1.45(<.001)$ & 30.49 & 39.86 \\
$\begin{array}{l}\text { Prior authorization } \\
\text { 2009: Yes(1) vs. No (0) }\end{array}$ & $8459.42(<.001)$ & $-10.40(.93) \dagger$ & 0.01 & .0002 \\
\hline
\end{tabular}

*With 1 and 46 degrees of freedom. Model significance is the same as regression coefficient significance.

$\dagger$ Prior authorization resulted in a $\$ 10.40$ reduction in out-of-pocket expenses $(\mathrm{p}=0.93)$. 
Table 4-5. Bivariate regression equations predicting total out-of-pocket expenses for sorafenib.

\begin{tabular}{|c|c|c|c|c|}
\hline Equation (Predictor) & Intercept (Sig) & $\begin{array}{l}\text { Regression } \\
\text { Coefficient }(p)\end{array}$ & $\begin{array}{l}\text { Model } \\
\text { F-ratio* }\end{array}$ & $\begin{array}{l}\text { R-square } \\
\text { (\%) }\end{array}$ \\
\hline $\begin{array}{l}\text { Monthly premiums } \\
2009\end{array}$ & $5728.06(<.001)$ & $14.27(<.001)$ & 200.28 & 81.32 \\
\hline Deductible 2009 & $6532.42(<.001)$ & $-1.45(<.001)$ & 30.49 & 39.86 \\
\hline Cost sharing 2009 (\%) & $5115.20(<.001)$ & $41.16(<.001)$ & 42.82 & 48.21 \\
\hline $\begin{array}{l}\text { Prior authorization } \\
\text { 2009: Yes (1) vs. No } \\
\text { (0) }\end{array}$ & $6414.08(<.001)$ & $-67.17(.50) \dagger$ & 0.46 & .0010 \\
\hline
\end{tabular}

*With 1 and 46 degrees of freedom. Model significance is the same as regression coefficient significance.

$\dagger$ Prior authorization resulted in a $\$ 67.17$ reduction in out-of-pocket expenses $(p=0.50)$.

Table 4-6. Bivariate regression equations predicting total out-of-pocket expenses for erlotinib.

\begin{tabular}{|c|c|c|c|c|}
\hline Equation (Predictor) & Intercept (Sig) & $\begin{array}{l}\text { Regression } \\
\text { Coefficient }(p)\end{array}$ & $\begin{array}{l}\text { Model } \\
\text { F-ratio* }\end{array}$ & $\begin{array}{l}\text { R-square } \\
\text { (\%) }\end{array}$ \\
\hline $\begin{array}{l}\text { Monthly premiums } \\
2009\end{array}$ & $4495.63(<.001)$ & $14.27(<.001)$ & 200.28 & 81.32 \\
\hline Deductible 2009 & $5299.98(<.001)$ & $-1.45(<.001)$ & 30.49 & 39.86 \\
\hline Cost sharing 2009 (\%) & $3882.77(<.001)$ & $41.16(<.001)$ & 42.82 & 48.21 \\
\hline $\begin{array}{l}\text { Prior authorization } \\
\text { 2009: Yes (1) vs. No } \\
\text { (0) }\end{array}$ & $5181.64(<.001)$ & $-67.17(.50) \dagger$ & 0.46 & .0010 \\
\hline
\end{tabular}

*With 1 and 46 degrees of freedom. Model significance is the same as regression coefficient significance.

$\dagger$ Prior authorization resulted in a $\$ 67.17$ reduction in out-of-pocket expenses $(\mathrm{p}=0.50)$. 
Table 4-7. Bivariate regression equations predicting total out-of-pocket expenses for dasatinib.

\begin{tabular}{lclcc}
\hline Equation (Predictor) & Intercept (Sig) & $\begin{array}{l}\text { Regression } \\
\text { Coefficient }(\boldsymbol{p})\end{array}$ & $\begin{array}{l}\text { Model } \\
\text { F-ratio* }\end{array}$ & $\begin{array}{l}\text { R-square } \\
(\%)\end{array}$ \\
\hline $\begin{array}{l}\text { Monthly premiums } \\
\text { 2009 }\end{array}$ & $5418.27(<.001)$ & $14.27(<.001)$ & 200.28 & 81.32 \\
Deductible 2009 & $6222.63(<.001)$ & $-1.45(<.001)$ & 30.49 & 39.86 \\
Cost sharing 2009 (\%) & $4805.41(<.001)$ & $41.16(<.001)$ & 42.82 & 48.21 \\
Prior authorization & $6058.34(<.001)$ & $-2.31(.98) \dagger$ & 0 & .98 \\
2009: Yes (1) vs. No & & & & \\
$(\mathbf{0})$ & & & & \\
\hline
\end{tabular}

*With 1 and 46 degrees of freedom. Model significance is the same as regression coefficient significance.

$\uparrow$ Prior authorization resulted in a $\$ 2.31$ reduction in out-of-pocket expenses $(p=0.98)$.

Table 4-8. Bivariate regression equations predicting total out-of-pocket expenses for sunitinib.

\begin{tabular}{|c|c|c|c|c|}
\hline Equation (Predictor) & Intercept (Sig) & $\begin{array}{l}\text { Regression } \\
\text { Coefficient }(p)\end{array}$ & $\begin{array}{l}\text { Model } \\
\text { F-ratio* }\end{array}$ & $\begin{array}{l}\text { R-square } \\
(\%)\end{array}$ \\
\hline $\begin{array}{l}\text { Monthly premiums } \\
2009\end{array}$ & $6947.76(<.001)$ & $14.27(<.001)$ & 200.28 & 81.32 \\
\hline Deductible 2009 & $7752.12(<.001)$ & $-1.45(<.001)$ & 30.49 & 39.86 \\
\hline Cost sharing $2009(\%)$ & $6334.90(<.001)$ & $41.16(<.001)$ & 42.82 & 48.21 \\
\hline $\begin{array}{l}\text { Prior authorization } \\
\text { 2009: Yes (1) vs. No } \\
\text { (0) }\end{array}$ & $7633.77(<.001)$ & $-67.17(.50) \dagger$ & 0.46 & .010 \\
\hline
\end{tabular}

*With 1 and 46 degrees of freedom. Model significance is the same as regression coefficient significance.

$\dagger$ Prior authorization resulted in a $\$ 67.17$ reduction in out-of-pocket expenses $(p=0.50)$. 
Table 4-9. Bivariate regression equations predicting total out-of-pocket expenses for vorinostat.

\begin{tabular}{llllc}
\hline Equation (Predictor) & Intercept (Sig) & $\begin{array}{l}\text { Regression } \\
\text { Coefficient }(\boldsymbol{p})\end{array}$ & $\begin{array}{l}\text { Model } \\
\text { F-ratio* }\end{array}$ & $\begin{array}{l}\text { R-square } \\
(\%)\end{array}$ \\
\hline $\begin{array}{l}\text { Monthly premiums } \\
\text { 2009 }\end{array}$ & $7589.62(<.001)$ & $14.27(<.001)$ & 200.28 & 81.32 \\
Deductible 2009 & $8393.97(<.001)$ & $-1.45(<.001)$ & 30.49 & 39.86 \\
Cost sharing 2009 (\%) & $6976.76(<.001)$ & $41.16(<.001)$ & 42.82 & 48.21 \\
Prior authorization & $8186.08(<.001)$ & $71.96(.43) \dagger$ & 0.62 & .43 \\
2009: Yes (1) vs. No & & & & \\
$(\mathbf{0})$ & & & & \\
\hline
\end{tabular}

*With 1 and 46 degrees of freedom. Model significance is the same as regression coefficient significance.

$\dagger$ Prior authorization resulted in a $\$ 71.96$ increase in out-of-pocket expenses $(p=0.43)$.

Table 4-10. Bivariate regression equations predicting total out-of-pocket expenses for nilotinib.

\begin{tabular}{lllll}
\hline Equation (Predictor) & Intercept (Sig) & $\begin{array}{l}\text { Regression } \\
\text { Coefficient }(\boldsymbol{p})\end{array}$ & $\begin{array}{l}\text { Model } \\
\text { F-ratio* }\end{array}$ & $\begin{array}{l}\text { R-square } \\
(\%)\end{array}$ \\
\hline $\begin{array}{l}\text { Monthly premiums } \\
\text { 2009 }\end{array}$ & $5982.82(<.001)$ & $14.27(<.001)$ & 200.28 & 81.32 \\
Deductible 2009 & $6787.17(<.001)$ & $-1.45(<.001)$ & 30.49 & 39.86 \\
Cost sharing 2009 (\%) & $5369.96(<.001)$ & $41.16(<.001)$ & 42.82 & 48.21 \\
Prior authorization & $6594.96(<.001)$ & $-19.99(.84) \dagger$ & 0.04 & .001 \\
2009: Yes (1) vs. No & & & & \\
$(\mathbf{0})$ & & & & \\
\hline
\end{tabular}

*With 1 and 46 degrees of freedom. Model significance is the same as regression coefficient significance.

$\dagger$ Prior authorization resulted in a $\$ 19.99$ reduction in out-of-pocket expenses $(p=0.84)$. 
Table 4-11. Bivariate regression equations predicting total out-of-pocket expenses for lapatinib.

\begin{tabular}{|c|c|c|c|c|}
\hline Equation (Predictor) & Intercept (Sig) & $\begin{array}{l}\text { Regression } \\
\text { Coefficient }(p)\end{array}$ & $\begin{array}{l}\text { Model } \\
\text { F-ratio* }\end{array}$ & $\begin{array}{l}\text { R-square } \\
(\%)\end{array}$ \\
\hline $\begin{array}{l}\text { Monthly premiums } \\
2009\end{array}$ & $3613.20(<.001)$ & $14.27(<.001)$ & 200.28 & 81.32 \\
\hline Deductible 2009 & $4417.56(<.001)$ & $-1.45(<.001)$ & 30.49 & 39.86 \\
\hline Cost sharing 2009 (\%) & $3000.34(<.001)$ & $41.16(<.001)$ & 42.82 & 48.21 \\
\hline $\begin{array}{l}\text { Prior authorization } \\
\text { 2009: Yes (1) vs. No } \\
\text { (0) }\end{array}$ & $4211.30(<.001)$ & $53.78(.61)$ & 0.27 & .006 \\
\hline
\end{tabular}

*With 1 and 46 degrees of freedom. Model significance is the same as regression coefficient significance.

$\dagger$ Prior authorization resulted in a $\$ 53.78$ increase in out-of-pocket expenses $(\mathrm{p}=0.61)$. 
Although not statistically significant in any of the models, the influence of prior authorization on out-of-pocket expenses varies, and in the case of vorinostat and lapatinib, there is an increase in out-of-pocket expenses. For the two study drugs requiring step therapy, dasatinib and nilotinib, the influence of prior authorization led to a decrease in out-of-pocket expenses by $\$ 2.31$ and $\$ 19.99$, respectively. 


\section{CHAPTER 5. DISCUSSION}

There is little doubt that for seniors lacking prescription drug benefits Medicare Part D is a substantial advantage. Many seniors have adequate prescription drug coverage through their retiree benefits, so Medicare Part D is of little consequence to them. However, Medicare Part D is a complex and confusing program that changes from year to year, as do some of the providers of benefits. In a study that examined Medicare beneficiaries understanding of the Part D drug benefit, the authors made several interesting findings. Among these findings it is estimated that only $40 \%$ of beneficiaries knew their drug plan included a coverage gap, and among the beneficiaries who were aware of the gap, only $50 \%$ knew the coverage gap started within $\pm \$ 250$ and stopped \pm $\$ 400$. The study further showed that among all beneficiaries, cost sensitive behavior occurred for those nearing or in the coverage gap. Some beneficiaries chose not to fill a new prescription (4.9\%), some took less than prescribed (6.5\%), and some did not refill their prescriptions $(8.2 \%){ }^{26}$

For beneficiaries with chronic illnesses and cancer, understanding plan design and drug utilization management can be a significant consideration when planning for out-ofpocket expenses. Providers may choose to offer a plan with lower deductibles or premiums to attract clients, but it is difficult for potential purchasers to know the full impact of how plan design may ultimately affect them.

Medicare Part D enrollees do not always choose a plan according to the lowest premium, according to a study from the Kaiser Family Foundation. The study suggests that the wide range of choices available in Part D plans may be a detriment to beneficiaries in their search for the best plan choice. Using one of three models, either looking at the previous years' expenses or looking forward at what drugs may be used, or the best match to their chosen plan, only 6 to 9 percent of seniors chose the lowest cost plan available to them. ${ }^{57}$ These results would suggest that seniors do not understand plan design well, or perhaps they are willing to pay more for the use of a certain pharmacy or for a plan with fewer restrictions such as prior authorization or step therapy.

\section{CONCLUSION}

\section{Discussion of Research Objectives}

\section{Research objective 1: Conduct a cost analysis of nine targeted oral cancer therapies under Medicare Part D plans in Tennessee.}

This analysis shows that plan design and drug utilization management are responsible for considerable variations in beneficiaries' total annual out-of-pocket costs for the nine study drugs across the 48 Medicare Part D plans in Tennessee. The ratio of 
highest to lowest price for the study drugs ranged from 1.14 for lenalidomide to 1.29 for lapatinib, even though the dollar value of out-of-pocket expenses remains constant.

Some possible explanations for this variation could be tier placement and whether a particular drug is on a plan's formulary at all. Although pricing guidelines issued annually to payers by CMS include the term "actuarial equivalence," the meaning is not specifically defined. There are no regulations that restrict tiered cost-sharing or limits on how the tiers are structured. The calculations determine only whether higher cost sharing tiers for some drugs are offset by lower cost sharing for other drugs, and this test is not required within each drug class. ${ }^{48}$ For example, Part D plans that place high cost drugs on a tier with a flat cost share approach may attract a disproportionate number of beneficiaries and shift costs to other plan design parameters. The impact of actuarial equivalence is only as sound as its enforcement. Table 5-1 demonstrates the variation in plan design affecting the nine drugs used in the analysis.

Considering each drug in each of the 48 plans available in the state of Tennessee for the year 2009, there is an out-of-pocket cost variation of $\$ 1,133$ per drug. For example, a patient taking imatinib may incur annual out-of-pocket costs that range from $\$ 4,562$ to $\$ 5,694$, depending on which plan they choose. This cost variation of $\$ 1,133$ is consistent for all drugs in the study, due to plan design parameters. There may be additional cost variations due to drug pricing variations at individual pharmacies, and beneficiaries may wish to compare prices between pharmacies to maximize out-of-pocket cost savings. CMS regulatory guidance states all Part D plans must cover all or substantially all drugs in the six classes of clinical concern. These drugs may be subject to tiering and prior authorization, and wide out-of-pocket variation is the result of varying other plan design parameters.

It would be difficult to discern which plan may offer the lowest out-of-pocket annual costs by simply looking at plan design parameters. In addition, if the diagnosis

Table 5-1. 2009 Medicare Part D plan design by drug.

\begin{tabular}{llcccc}
\hline Drug Name & $\begin{array}{l}\text { \% Plans } \\
\text { with Drug } \\
\text { on } \\
\text { Formulary }\end{array}$ & $\begin{array}{l}\text { Primary } \\
\text { Tier } \\
\text { Placement }\end{array}$ & $\begin{array}{l}\text { \%o of Plans } \\
\text { with Prior } \\
\text { Authorization }\end{array}$ & $\begin{array}{l}\text { \% of } \\
\text { Plans with } \\
\text { Step } \\
\text { Therapy }\end{array}$ & $\begin{array}{l}\text { Primary } \\
\text { Cost- } \\
\text { Sharing } \\
\text { Range \% }\end{array}$ \\
\hline Imatinib & 100 & 4 & 79 & 0 & $25-50$ \\
\hline Lenalidomide & 100 & 4 & 81 & 0 & $25-50$ \\
Sorafenib & 100 & 4 & 71 & 0 & $25-50$ \\
Erlotinib & 100 & 4 & 69 & 0 & $25-50$ \\
\hline Dasatinib & 100 & 4 & 71 & 13 & $25-50$ \\
\hline Sunitinib & 100 & 4 & 71 & 0 & $25-50$ \\
Vorinostat & 100 & 4 & 58 & 0 & $25-50$ \\
\hline Nilotinib & 100 & 4 & 69 & 19 & $25-50$ \\
\hline Lapatinib & 100 & 4 & 71 & 0 & $25-50$ \\
\hline
\end{tabular}


and initiation of therapy begins between plan years, there is no option to change plans in order to save on out-of-pocket expenses, placing most enrollees in the doughnut hole early in their treatment.

\section{Research objective 2: Examine pricing structure trends from 2008 to 2009 and their impact on beneficiaries' out-of-pocket expenses for nine targeted oral cancer drugs.}

Deductibles. CMS guidelines for Part D plans in 2009 included a maximum deductible of $\$ 295$. This study found deductibles from $\$ 0$ to $\$ 295$, with $58.3 \%$ of the plans in Tennessee charging $\$ 0$ deductible, $29.2 \%$ charging the maximum deductible, with the remaining $12.5 \%$ charging varying amounts between the minimum and maximum. This is consistent with 2008 data, when the maximum deductible was \$275. The maximum deductible has increased every year since the inception of Part D on January 1, 2006. Along with using the maximum deductible in plan design, Part D plans are allowed to charge up to the coinsurance limit while using the maximum deductible as well. Two of the 48 plans in 2009 utilized the maximum deductible as well as costsharing above the CMS guidelines. As might be expected, these two plans had some of the highest out-of-pocket costs for the nine drugs in the study.

Premiums. In most cases monthly premiums increased from 2008 to 2009 . In $23.4 \%$ of the plans there was an increase up to $\$ 5$, another $23.4 \%$ of plans showed a $\$ 5$ 10 increase, and $29 \%$ of plans had a premium increase of more than $\$ 10$. The mean change in monthly premiums was from $\$ 39.26$ to $\$ 44.73$, an increase of $21.5 \%$. Figure 5-1 shows the range of change in premiums from 2008 to 2009.

In one plan where monthly premiums dropped significantly from 2008 to 2009, cost sharing for drugs in the class of study drugs increased from $25 \%$ to $33 \%$. Another plan with a significant increase in premiums also increased cost sharing for these drugs from $25 \%$ to $44 \%$.

The regression models demonstrated that increases in monthly premiums were most strongly associated with increases in annual out-of-pocket spending. For every $\$ 1$ increase in monthly premium, annual out-of-pocket expenses increased by $\$ 14.29$ for imatinib $(\mathrm{p}<.001)$. When evaluated at the mean of monthly premiums, this parameter adds $\$ 639.33$ to the adjusted mean annual out-of-pocket expenses. For lenalidomide, sorafenib, erlotinib, dasatinib, sunitinib, vorinostat, nilotinib and lapatinib every $\$ 1$ increase in monthly premiums resulted in an annual out-of-pocket increase of \$14.27 $(\mathrm{p}<.001)$. Since the inception of Medicare Part D in 2006 until the release of plan information for 2011, the average Part D premium has risen by $57 \%{ }^{58}$

Cost Sharing. Changes in cost sharing from 2008 to 2009 varied widely among the plans from those that had no change, those that increased, and those that decreased, similar to premiums. Of the 48 plans in the study, approximately $73 \%$ of the plans had no change to their cost sharing structure, while $13.3 \%$ had decreases, and $13.3 \%$ had increases ranging from $2 \%$ to $19 \%$. Every $1 \%$ increase in cost sharing is associated with a 


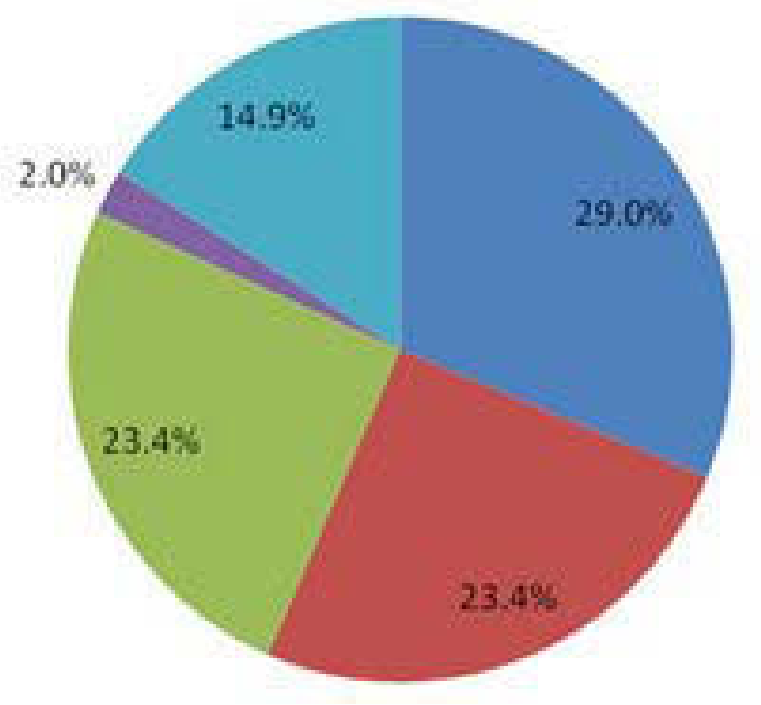

a increase $>\$ 10$

increase $\$ 5-\$ 10$

Increase up to \$5

Nochange

Any Decrease

Figure 5-1. Premium changes from 2008 to 2009.

$\$ 41.45$ increase in out-of-pocket expenses for imatinib. That same 1\% increase in cost sharing resulted in a $\$ 41.16$ increase in out-of-pocket expenss for lenalidomide, sorafenib,m erlotinib, dasatinib, sunitinib, vorinostat, nilotinib and lapatinib.

Prior Authorization. The use of prior authorization increased dramatically from 2008 to 2009 , and varied depending on the drug in question. Although not statistically significant in any of the models, the use of prior authorization resulted in lower total outof-pocket costs for imatinib, lenalidomide, sorafenib, erlotinib, dasatinib, sunitinib, and nilotinib. Two of the study drugs, vorinostat and lapatinib, were subject to step therapy, and the use of prior authorization resulted in higher out-of-pocket costs. Those findings were not statistically significant either. None of the plans in the study used prior authorization as part of their overall plan design in 2008 for the study drugs, whereas all of the drugs on a mean of $65.1 \%$ of plans in the study were subject to prior authorization in 2009 , and two drugs on a mean of $15.7 \%$ of plans required step therapy as well.

\section{Research objective 3: Analyze the relationship between drug utilization management techniques used by Medicare Part $D$ plans and access to medications under CMS guidelines.}

The regressions showed that higher deductibles were associated with lower outof-pocket costs by $\$ 1.45$ for every $\$ 1$ increase in deductibles. This number was consistent across all the drugs in the study. The R-square value of 39.86 in this regression indicates that about $40 \%$ of the variation in out-of-pocket spending is the result of deductibles. This is certainly not an intuitive calculation and would be easily overlooked by consumers when pricing various plans. 
Another important element is monthly premiums. For every $\$ 1$ increase in premiums, out-of-pocket expenses increase by $\$ 14.29$ for imatinib, and $\$ 14.27$ for the remainder of the study drugs. Lower monthly premiums is another technique used by plan designers to entice consumers, as opposed to lower pricing of drugs, which occurred at the inception of Part D or at the introduction of a new plan to the marketplace. The R-square value shows that about $80 \%$ of the variation in out-of-pocket spending is due to monthly premiums, which cover a range from $\$ 17.60$ to $\$ 100.70$. The danger in charging low monthly premiums is attracting a disproportionate share of members taking costly specialty drugs. Plan structure changes annually and for some plans leads to sharp premium increases in the next plan year.

Cost sharing is one of the most important elements for the study drugs. Regression results showed that approximately $40 \%$ of the variation in out-of-pocket expenses were due to cost sharing. All of the study drugs throughout the various plans were subject to a coinsurance payment design of cost sharing, reserved for specialty or other high cost drugs. Coinsurance rates for Part D plans in Tennessee range from 25\% to $44 \%$.

At the time of this study, all of the study drugs were brand name products and subject to specialty tiering or were placed in the highest formulary tier of the 48 plans included in study. Pharmacy benefits management groups that provide Part D coverage have placed the newer oral oncology drugs in their specialty tier or classified them as non-preferred brand medications. Placement of a drug in a specialty tier cannot be appealed by a beneficiary as one could appeal placement on a preferred or non-preferred tier. $^{59}$

All of the drugs in the study (imatinib, lenalidomide, sorafenib erlotinib, dasatinib, sunitinib, vorinostat, nilotinib and lapatinib) are only available as brand name products. Generic drugs offer substantial savings to Part D enrollees, and some plans offer coverage for generic drugs in the coverage gap, or doughnut hole. There is some expectation that competition from generic manufacturers will lower prices for drugs, but for the aforementioned targeted oral oncology drugs, this may not be possible in the near future.

\section{Additional Information}

Although not measured in this study, even with oral chemotherapy there exists the problem of nonadherence. Recently the ADAGIO (Adherence Assessment with Gleevec: Indicators and Outcomes) study in Belgium showed only $14 \%$ of patients were fully adherent to therapy. ${ }^{60}$ In their investigation, cost was not a factor because of the national healthcare system in Belgium. There are some possible explanations for this phenomenon. From the physicians' perspective, current compensation models do not adequately cover expenses related to all aspects of oral chemotherapy use such as coordinating drug delivery, filling out forms associated with third party payment, as well as increased monitoring and counseling for toxicities and adherence. ${ }^{59}$ 
Another study of compliance and persistency measured the prescription-filling activities of oncology patients using imatinib for both chronic myelogenous leukemia (CML) and gastrointestinal stromal tumors (GIST). It was found that overall compliance was $78 \%$ in the CML patients and $73 \%$ in the GIST patients. The authors noted that suboptimal compliance and persistency may result in plasma levels that may be inadequate to kill cancer cells, increasing the risk of relapse and progression. ${ }^{62}$ In another analysis of Medicare Part D enrollees by Hoadley et al., it was shown that for patients with chronic conditions about $20 \%$ of those who reached the coverage gap either stopped taking their medication or reduced the frequency of administration. ${ }^{63}$

Some other barriers to successful oral chemotherapy use may be drug and food interactions in addition to the effects of cancer on drug absorption through the gastrointestinal tract. One drug in particular, lapatinib, is labeled to be taken at least one hour before or one hour after food. However, a recently published editorial points out that the bioavailability of lapatinib is greatly increased by food, especially a high fat meal. ${ }^{64}$ This was disclosed at the 2007 meeting of the American Society for Clinical Pharmacology and Therapeutics and further states that this is how the phase III study was carried out. The sponsors did not know the results of the food effect study and thus could not recommend anything other than the dose that appears in the prescribing information.

In terms of the economic impact of this information, if the drug were administered with food, a $60 \%$ savings, or about $\$ 1,700$ a month, would result when based on the 1500 $\mathrm{mg}$ dose used in clinical trials. The use of strong cytochrome P-450 inhibitors is also being studied to increase drug bioavailability in order to decrease costs. ${ }^{64}$. Formal pharmacokinetic studies should be the basis for such dosing, and in the case of costly agents such as lapatinib, would seem worthwhile. The impetus for such studies should come from the federal government along with private payers and patient advocacy groups.

Seniors have stated in national surveys ${ }^{26,62}$ that they lack real understanding of the Medicare Part D benefit. The Gruber study demonstrated the extent to which this occurs. Based on 2006 drug use, seniors who did not choose the lowest cost plan would have saved between $\$ 360$ and $\$ 520$ on average annually if they had chosen the lowest-cost plan. $^{57}$ include:

Some suggestions to help streamline plan design and increase understanding

- Reducing the number of plans available, as many plans are indistinguishable from one another. Within the 48 plans studied, there was as little as a $\$ 0.10$ difference in monthly premium for some plans, and six plans charged the same premium. Standardize benefits within the plans by limiting the number of options for copayments, deductibles, cost-sharing, and gap coverage. The range for costsharing in the study ranged from $25-44 \%$ for imatinib, and deductibles ranged from the minimum of $\$ 0$ to the maximum allowed by CMS of $\$ 295$. 
- Standardize language used in plans such as for "preferred" or "brand name" or "specialty," "non-preferred brand." The plans in this study used tiers 3 through 6 as well as the previous terms to describe the same drug.

- Utilize accepted treatment guidelines and standards of care in coverage decisions. For example, standard therapy for a disease state should be covered at a lower cost-sharing level regardless of whether the drug is only available as a brand name product (as with the study drugs)

- Make gap coverage insurance available. The study results show that only 11 of the 48 available plans have gap insurance available, and even then only cover generic drugs

An effort to restructure and simplify Medicare Part D could increase enrollment, adherence, and improve the health of seniors. For Part D beneficiaries with cancer, these efforts would enhance quality of life and lower out-of pocket spending.

Over the first five years of Medicare Part D, a number of changes have occurred that have affected coverage and costs for beneficiaries. These changes are highlighted in a data spotlight report by Hoadley et al. for the Kaiser Family Foundation. ${ }^{1}$ Of particular interest are the changes to benefit design and cost sharing, the use of specialty tiers, and formularies and utilization management.

A review of benefit design and cost sharing over the first five years showed that most plans do not offer the defined standard benefit. Rather, the majority now offer a tiered cost-sharing structure, with a four-tiered approach that consists of generic drugs, preferred brand drugs, non-preferred brand drugs, and specialty drugs. Only $11 \%$ of plans do not utilize tiers in their structure, and an increasing number of plans have implemented a two generic-tier structure. Use of a deductible is now present in $60 \%$ of Part D plans compared to 40 to $45 \%$ in previous years. The median cost sharing for a 30 day supply of "non-preferred" brand name drugs has increased by $39 \%$ since 2006 , while "preferred" drug cost sharing has increased by $50 \%$.

The use of specialty tiers for medications costing at least $\$ 600$ per month has increased over the five year period to $89 \%$ of plans now using a specialty tier. Plans with a specialty tier generally have higher coinsurance rates ranging from 25 to $33 \%$ according to CMS guidelines; however, plans are allowed to impose higher cost sharing if that cost is offset by a lower deductible.

Formularies and utilization management techniques still vary widely in Part D plans. Most Part D plans include more drugs on their formulary than CMS requires, approximately $87 \%$ of drugs, while other plans list only $62 \%$ of drugs from the CMS drug reference file. Part D plan beneficiaries can still request an exception to have an offformulary drug covered, or they can purchase the drug at their own expense. Other utilization management techniques such as step therapy, prior authorization, and quantity limits still may restrict access to a drug even if it is listed on the plan's formulary. Since 2007 , some form of utilization management techniques have increased from 18\% in 2007 to $28 \%$ in $2010 .^{1}$ 
As shown in the Kaiser Family Foundation Report, Medicare Part D seems to be constantly evolving ${ }^{1}$. All of the aforementioned Part D plan features are key to beneficiaries' out-of-pocket expenses and could have important implications for access.

In 2011, pharmaceutical manufacturers began offering_a brand-name drug discount of $50 \%$ for purchases made in the coverage gap period. Additionally, CMS is implementing other regulations that may result in consolidation of Part D plans, perhaps eliminating plans that do not provide a demonstrative difference. The Affordable Care Act of 2010 provides for a rebate of $\$ 250$ for Part D enrollees reaching the coverage gap and will gradually reduce cost sharing for both brand and generic drugs in the coverage gap until it reaches the $25 \%$ level in 2020 , eliminating the gap altogether. ${ }^{65}$

\section{LIMITATIONS}

The current study did not utilize actual claims data, which could lead to variations in cost information. Additionally, there are no outcomes or effectiveness information included in this study. Data for this study was limited to the state of Tennessee, and only utilized information from 2008 and 2009.

Average wholesale price (AWP) was used to calculate drug costs for the study. The basis for this was the use in other studies, although it may provide an overerestimate of actual costs. Actual acquisition costs (AAC) may provide a more accurate estimate of a beneficiaries' out-of-pocket costs, since this price structure includes rebates and discounts, especially important to government payers. ${ }^{66}$

\section{FUTURE RESEARCH}

A large percentage of oncology drugs in late stage development are targeted therapies in oral dosage forms. In addition, manufacturers will likely seek expanded indications for their existing therapies. An assessment of the potential financial impact of these drugs on the marketplace as they are replacing or are added to existing therapies would be of great interest to payers and healthcare providers.

Physicians' awareness and attitudes toward costs of treatments and costeffectiveness is increasing, as demonstrated by a national survey of oncologists conducted in 2008. ${ }^{44}$ Fifty-eight percent of those surveyed stated that "patients should have access to effective cancer treatments only if they provide good value for the money" (Nadler et.al., p. 198). Only 42\%, however, felt they were prepared to interpret and use cost-effectiveness information in treatment decisions. In addition, $64 \%$ of oncologists surveyed stated that Medicare reimbursement rates for oral agents limited their ability to prescribe them to their patients. From a policy perspective, $80 \%$ of oncologists favored more cost effectiveness data in coverage decisions and $79 \%$ believe that the government should conduct more research on comparative effectiveness of cancer drugs. ${ }^{44}$ 
Comparative effectiveness research (CER) is an increasingly visible strategy that will undoubtedly play a role in the future of healthcare including Medicare, as the American Reinvestment and Recovery Act (ARRA) allocated \$1.1 billion to comparative effectiveness research. The Institute of Medicine has identified 100 high priority areas for $\mathrm{CER}^{67}$, with hematology and oncology ranking in the top 15 categories. A comprehensive, comparative effectiveness research program will aid in identifying the most effective options and link data from public and private entities to build upon data collection and research efforts. These processes should ensure that information gained is incorporated into clinical practice guidelines and will better inform patients, clinicians, and payers. The role of pharmacists in comparative effectiveness research will include recommendations used in national guidelines that will influence formulary tier placement and ultimately reimbursement for the preferred agents. This will also provide additional data in order to track and trend adverse events, implement strategies for high-risk drugs, and plan for new agents.

The information obtained from this study could be used by payers to aid in plan design as well as healthcare administration officials in other states to better understand the role of plan design as it affects their beneficiaries. The Affordable Care Act of 2010, which additionally provides a rebate for beneficiaries who reach the coverage gap, will eventually eliminate the coverage gap. This step, along with other statutory changes may affect how the program works in the future. 


\section{LIST OF REFERENCES}

1. Hoadley J, Summer L, Hargrave E, et al. Medicare Part D 2010 Data Spotlight. Medicare Prescription Drug Plans in 2010 and Key Changes over Five Years: Summary of Findings. September 2010. Available at: www.kff.org/medicare/upload/8096.pdf. Accessed October 30, 2010.

2. U. S. Census Bureau: U. S. Interim Projections by Age, Sex, Race and Hispanic Origin, 3/04 update. Available at http://www.census.gov/ipc/www/usinterimproj/. Accessed February 2, 2009.

3. National Cancer Institute. SEER database. Available at: http://seer.cancer.gov/statistics/. Accessed February 4, 2009.

4. Espey DK, Wu XC, Swan J, et. al. Annual Report to the Nation on the Status of Cancer, 1975-2004; Featuring Cancer in American Indians and Alaska Natives. Cancer. 2007; 110(10):2119-2152.

5. Bradbury K, Cleary K, et al. (2008) (2010). Medco Drug Trend Report. Available at: http://medco.mediaroom.com/index.php?s=64\&cat=5. Accessed February 2, 2009 and March 6, 2011.

6. New Drug Approvals. Pharmacist's Letter/Prescriber's Letter 2008 edition. Available at: www.pharmacistsletter.com. Accessed Dec. 10, 2008.

7. Nexavar [package insert]. Wayne, NJ: Bayer Pharmaceuticals; 2009.

8. Revlimid [package insert]. Summitt, NJ: Celgene Corp.; 2009.

9. List A, Dewald G, Bennett J. Lenalidomide in the Myelodysplastic Syndrome with Chromosome 5q Deletion. New England Journal of Medicine. 355:1456, October 5, 2006.

10. Tykerb [package insert]. Research Triangle Park, NC: Glaxo Smith Kline; 2008.

11. Gleevec [package insert]. East Hanover, NJ: Novartis Pharmaceuticals; 2008.

12. Tasigna [package insert]. East Hanover, NJ: Novartis Pharmaceuticals; 2007.

13. Tarceva [package insert]. Melville, NY: OSI Pharmaceuticals; Genentech Pharmaceuticals; 2010.

14. Shepherd FA, Pereira JR, Tudor C, et al. Erlotinib in previously treated non-smallcell lung cancer. New England Journal of Medicine. 2005; 353(2):123-132. 
15. Zolinza [package insert]. Whitehouse, NJ: Merck \& Co.; 2008.

16. Bach PB, McClellan MB. The First Months of the Prescription Drug Benefit-A CMS Update. New England Journal of Medicine. 2006; 354(22):2312-2314.

17. The Medicare Payment Advisory Commission. Part D Payment System: Payment Basics. Available at http://www.medpac.gov/documents/MedPAC_Payment_Basics_08_PartD.pdf Accessed February 7, 2009.

18.Miller SB, Hoffman TA, Houts JC, et al. The Rise of Specialty Pharmacy Costs: Issues for Providers, Payers, and Patients. Disease Management and Health Outcomes. 2007; 15(2):83-89.

19. Potential Cost Impacts Resulting from CMS Guidance on "Special Protections for Six Protected Drug Classifications" and Section 176 of the Medicare Improvements for Patients and Providers Act of 2008 (MIPPA). Available at www.milliman.com. Accessed October 16, 2008.

20. Huskamp HA, Keating NL. The New Medicare Drug Benefit: Formularies and Their Potential Effects on Access to Medications. Journal of General Internal Medicine. 2005; 20(7):662-665.

21. Eastman P. Policy Forum: Increased Cost-Shifting to Cancer Patients Could Adversely Affect Care. Oncology Times. 2009; 31(2):6-9. Available at: http://journals.lww.com/oncology-times/toc/2009/01250. Accessed January 25, 2009.

22. Etheredge LM. Medicare's Future: Cancer Care. Health Affairs. 2009; 28(1):148159.

23. Ke X, Hendrick F, Shaffer T, and Davidoff AJ. Out-of-pocket Spending Burden for Medicare Beneficiaries with Cancer. Journal of Clinical Oncology. 2010; 28(15) (May 20 Supplement):9124.

24. Weingart SN, Brown E, Bach PB, et al. NCCN Task Force Report: Oral Chemotherapy. Journal of the National Comprehensive Cancer Network. 2008; 6 (suppl 3):S1-S14.

25. Klepper B, Pauker D. Medicare's drug plan: Huge Price Disparities for Common Cancer Drugs. Community Oncology. 2006; 3(12):753-755.

26. Hsu J, Fung V, Price M, et al. Medicare Beneficiaries' Knowledge of Part D Prescription Drug Program Benefits and Responses to Drug Costs. Journal of the American Medical Association. 2008;299(16):1929-1936. 
27. National Survey of Pharmacists and Physicians, Findings on Medicare Part D. Kaiser Family Foundation, September 2006. Available at www.kff.org/kaiserpolls. Accessed February 20, 2010.

28. Eastman P. Policy Forum: Increased Cost-Shifting to Cancer Patients Could Adversely Affect Care. Oncology Times. 2009; 31(2):6-9. Available at: http://journals.lww.com/oncology-times/toc/2009/01250. Accessed January 25, 2009.

29. Hargrave E, Hoadley J, Merrell K, Cubanski J. Medicare Part D 2008 Data Spotlight: Specialty Tiers. The Henry J. Kaiser Family Foundation, December 2007. Available at http://www.kff.org/medicare/upload/7711.pdf. Accessed January 25, 2009.

30. Nelson R. High Cost Deters Patients from Imatinib Treatment. Medscape Medical News, August 5, 2010. Available at http://www.medscape.com/viewarticle/726371. Accessed November 26, 2010.

31. The Medicare Payment Advisory Commission. A Data Book: Healthcare Spending and the Medicare Program, June 2008, pages 160-175. Available at www.medpac.gov. Accessed March 3, 2009.

32. Curtiss FR. Pharmacy Benefit Spending on Oral Chemotherapy Drugs. Journal of Managed Care Pharmacy. 2006;12(7):570-577.

33. Dial E, Duh M, Fournier A, et al. Cost implications of intravenous bevacizumab treatment in patients with renal cell carcinoma: A retrospective claims database analysis. Journal of Clinical Oncology. 2009; 27(15) (May 20 Supplement):5112.

34. Bach PB. Costs of Cancer Care: A view from the Centers for Medicare \& Medicaid Services. Journal of Clinical Oncology. 2007; 25(2):187-190.

35. US Government Accountability Office. Medicare Part D: Spending, Beneficiary Cost-Sharing, and Cost-Containment Efforts for High-Cost Drugs Eligible for a Specialty Tier; January 2010. Available at http://www.gao.gov/new.items/d10242.pdf. Accessed March 23, 2010.

36. Adams KT. Oral Oncologics Join the War on Cancer. Biotechnology Healthcare. June 2007:24-31. Available at http://www.biotechnologyhealthcare.com/journal/fulltext/4/3/BH0403024.pdf?CFID= 81308217\&CFTOKEN=90147771. Accessed August 6, 2008.

37. Cohen J, Young B, Rochon S, Faden L. Are Medicare plans complying with CMS regulation? Expert Reviews in Pharmacoeconomic Outcomes Research. 2008; 8(2):133-139. 
38. Bowman J, Rousseau, Silk D, Harrison C. Access to cancer drugs in Medicare Part D: Formulary placement and beneficiary cost sharing in 2006. Health Affairs. 2006; 5(25):1240-1248.

39. The Medicare Coverage Database. Available at http://www.cms.gov/mcd/overview.asp. Accessed October 30, 2010.

40. Manning WG, Newhouse JP, Duan N, Keeler EB, Benjamin B, Liebowitz A, et al. Health insurance and the demand for medical care. Evidence from a randomized experiment. Santa Monica, CA: RAND Corporation, 1988. Report R-3476-HHS. Available at http://www.rand.org/content/dam/rand/pubs/reports/2005/R3476.pdf. Published February 1988. Accessed March 23, 2010.

41. Hsu J, Price M, Huang J, et al. Unintended consequences of caps on Medicare drug benefits. New England Journal of Medicine. 2006; 354(22):2349-2359.

42. Polinski JM, Mohr PE, and Johnson L. Impact of Medicare Part D on access to and cost sharing for specialty biologic medications for beneficiaries with rheumatoid arthritis. Arthritis and Rheumatism. 2009; 61(6):745-754.

43. Stuart B, Simoni-Wastila L, Chauncey D. Assessing the Impact of Coverage Gaps in the Medicare Part D Drug Benefit. Health Affairs, Web Exclusive, April 19, 2005. Available at http://proquest.umi.com/pqdlink?index $=3 \&$ did $=911043671 \&$ SrchMode $=3 \&$ sid $=2 \& \mathrm{~F}$ $\underline{\mathrm{mt}=3 \& \mathrm{VInst}=\mathrm{PROD} \& \mathrm{VType}=\mathrm{PQD} \& \mathrm{RQT}=309 \& \mathrm{VName}=\mathrm{PQD} \& \mathrm{TS}=1300742779 \& \mathrm{c}}$ lientId=45247\&aid=1. Accessed February 20, 2007.

44. Neumann PJ, Palmer JA, Nadler E, et al. Cancer Therapy Costs Influence Treatment: A National Survey of Oncologists. Health Affairs. 2010; 29(1):196-202.

45. Nadler E, Broderick WC, Zarotsky V and Kim J. How do medical and pharmacy directors perceive the value of new cancer drugs? Drug Benefit Trends. 2009; 21(4):120-130.

46. Diamond F. Leading with Its Heart Program. Managed Care. January 2008:16-22. Available at: http://www.managedcaremag.com/archives/0801/0801.warranty.html. Accessed March 23, 2010.

47. Choudhry NK, Fischer MA, Avorn J, et al. At Pitney Bowes, value-based insurance design cut copayments and increased drug adherence. Health Affairs. 2009; 29(11):1995-2001.

48. Lee TH, Emanuel EJ. Tier 4 drugs and the fraying of the social compact. New England Journal of Medicine. 2008; 359(4):333-335. 
49. PDP Drug Finder-Q1 Medicare.com. Available at: http://www.q1medicare.com/PartD-SearchPDPMedicarePartDDrugFinder.php. Accessed January 30, 2009.

50. Sprycel [package insert]. Princeton, NJ: Bristol-Myers Squibb; 2010.

51. Sutent [package insert]. New York, NY: Pfizer Labs; 2010.

52. Micromedex® Healthcare Series [Internet database]. Greenwood Village, CO: Thomson Reuters (Healthcare) Inc. Updated periodically.

53. McEvoy GK, ed in chief, Snow ED, ed. AHFS: Drug Information. Bethesda, MD: American Society of Health-System Pharmacists; 2008.

54. Murray L, Philippi E, editors. Red Book. 2008 ed. Montvale, NJ: Thompson Healthcare; 2008.

55. SAS version 9.2 Copyright (c) 2002-2008 by SAS Institute Inc., Cary, NC, USA.

56. PDP Enrollment by State. Available at www.cms.gov/MCRAdvPartDEnrolData/MPDESCC/itemdetail.asp. Accessed May $18,2009$.

57. Gruber J. Choosing A Medicare Part D Plan: Are Medicare Beneficiaries Choosing Low-Cost Plans? The Henry J. Kaiser Family Foundation, March 2009. Available at: www.kff.org. Accessed May 5, 2009.

58. Hoadley J. Cubanski J, Hargrave E, et. al. Medicare Part D Data Spotlight: Part D Plan Availability and Key Changes Since 2006. Available at: http://www.kff.org/medicare/upload/8107.pdf. Accessed April 5, 2011.

59. Hargrave E, Hoadley J, Summer L, et. al. Medicare Part D Data Spotlight: Coverage of Top Brand-Name and Specialty Drugs. Available at: http://www.kff.org/medicare/upload/8095.pdf. Accessed April 5, 2011.

60. Noens L, van Lierde MA, De Bock R, et al. Prevalence, determinants and outcomes of nonadherence to imatinib therapy in patients with chronic myeloid leukemia: The ADAGIO Study. Blood. 2009; 113(22):5401-5411.

61. Carroll J. Oncologists plead for fairer drug payments. Managed Care. November 2008:32-34.

62. Tsang J, Rudychev I, Pescatore SL. Prescription compliance and persistency in chronic myelogenous leukemia (CML) and gastrointestinal stromal tumor (GIST) patients on imatinib. Journal of Clinical Oncology. 2006; 24(18S) (June 20 Supplement): 6119. 
63. Hoadley J, Hargrave E, Cubanski J, Neuman T. The Medicare Part D Coverage Gap: Costs and Consequences in 2007. August 2008. Available at:

http://www.kff.org/medicare/upload/7811.pdf. Accessed March 23, 2010.

64. Ratain MJ, Cohen EE. The value meal: How to save $\$ 1,700$ per month or more on lapatinib. Journal of Clinical Oncology. 2007; 25(23):3397-3398.

65. Focus on Health Reform. Summary of New Health Reform Law. The Henry J. Kaiser Family Foundation. Available at http://www.kff.org/healthreform/upload/8061.pdf. Accessed November 28, 2010.

66. Mullins CD, Seal B, Seoane-Vazquez E, et al. Good research practices for measuring drug costs in cost effectiveness analyses: Medicare, Medicaid and other US government payer perspectives: The ISPOR Drug Task Force Report-Part IV. Value in Health. 2010; 13(1):18-24.

67. Committee on Comparative Effectiveness Research Prioritization, Institute of Medicine. Initial National Priorities for Comparative Effectiveness Research. Washington, D.C., National Academies Press, 2009. 


\section{VITA}

Eve Elias was born in Memphis, TN, in 1960. She received her doctor of pharmacy degree from the University of Tennessee College of Pharmacy in May 2005 and worked as a clinical staff pharmacist until January 2007. In February 2007, she entered a two-year Drug Information residency, concurrently pursuing a master's degree in Health Policy and Outcomes Research. She currently is a Clinical Assistant Professor at University of Missouri Kansas City's satellite campus in Columbia, Missouri, where she is the Director of Drug Information. She plans to graduate in May 2011. 